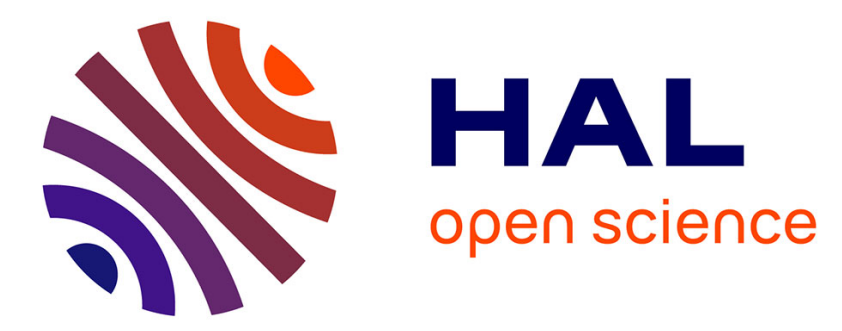

\title{
Optimal Redistributive Taxation in a Search Equilibrium Model
}

Mathias Hungerbuehler, Etienne Lehmann, Alexis Parmentier, Bruno van Der Linden

\section{- To cite this version:}

Mathias Hungerbuehler, Etienne Lehmann, Alexis Parmentier, Bruno van Der Linden. Optimal Redistributive Taxation in a Search Equilibrium Model. Review of Economic Studies, 2006, 73 (3), pp.743-767. 10.1111/j.1467-937X.2006.00394.x . hal-01248161

\section{HAL Id: hal-01248161 \\ https://hal.univ-reunion.fr/hal-01248161}

Submitted on 25 Feb 2016

HAL is a multi-disciplinary open access archive for the deposit and dissemination of scientific research documents, whether they are published or not. The documents may come from teaching and research institutions in France or abroad, or from public or private research centers.
L'archive ouverte pluridisciplinaire HAL, est destinée au dépôt et à la diffusion de documents scientifiques de niveau recherche, publiés ou non, émanant des établissements d'enseignement et de recherche français ou étrangers, des laboratoires publics ou privés. 


\title{
Optimal Redistributive Taxation in a Search Equilibrium Model.*
}

\author{
Mathias HUNGERBÜHLER ${ }^{\text {a }}$ \\ mathias.hungerbuhler@fundp.ac.be \\ Etienne LEHMANN b c e \\ elehmann@u-paris2.fr \\ $\begin{array}{cc}\text { Alexis PARMENTIER }{ }^{\mathbf{c}} \mathbf{~ b} & \text { Bruno VAN DER LINDEN } \mathbf{~} \mathbf{f} \text { e b } \\ \text { aparment@univ-paris1.fr } & \text { vanderlinden@ires.ucl.ac.be }\end{array}$
}

November 16, 2005

\begin{abstract}
This paper characterizes optimal non-linear income taxation in an economy with a continuum of unobservable productivity levels and endogenous involuntary unemployment due to frictions in the labor markets. Redistributive taxation distorts labor demand and wages. Compared to their efficient values, gross wages, unemployment and participation are lower. Average tax rates are increasing. Marginal tax rates are positive, even at the top. Finally, numerical simulations suggest that redistribution is much more important in our setting than in a comparable Mirrlees (1971) setting.
\end{abstract}

Keywords: Optimal Income Taxation, Unemployment, Wage Bargaining, Matching

JEL numbers: D82, H21, H24, J64.

a Department of Economics, University of Namur, Rempart de la Vierge 8, 5000 Namur, Belgium.

b ERMES, Université Paris 2, 12 Place du Panthéon, 75230 Paris Cedex 05, France.

c Department of Economics - IRES, Université Catholique de Louvain, Place Montesquieu, 3, B1348 Louvain La Neuve, Belgium.

d EUREQua, Université Paris 1, 106-112 Boulevard de l'Hôpital 75231 Paris Cedex 13, France.

e IZA, Bonn, Germany.

${ }^{\mathrm{f}}$ FNRS, Belgium.

\footnotetext{
${ }^{*}$ We thank participants in seminars at EUREQua, the Day for Belgian Labour Economists, CREST, AFSE, Namur, Evry, T2M 2004, ESEM 2004, EALE 2004, IDEI and S $^{\text {t }}$ Etienne. We thank Antoine d'Autume, Robin Boadway, Pierre Cahuc, Bart Cockx, Per Engström, Jean Michel Grandmont, Jean Hindriks, Herwig Immervoll, Francis Kramarz, Guy Laroque, David Margolis, Dominique Meurs, Gwenaël Piaser, Thomas Piketty, Fabien Postel Vinay, Jean Charles Rochet, Emmanuel Saez, Etienne Wasmer, Fabrizio Zilibotti and the two anonymous referees. The usual caveat applies. The authors acknowledge financial support from the Belgian Federal Government (Grant PAI P5/21, "Equilibrium theory and optimization for public policy and industry regulation"). This research has been done while Hungerbühler was at IRES and ERMES. Hungerbühler additionally thanks the Centre Cournot for Economic Studies for financial support.
} 


\section{Introduction}

This paper studies optimal non-linear income taxation in an economy with search frictions and private information about productivity levels. As in the seminal article of Mirrlees (1971), the government wants to redistribute incomes from more to less productive agents, but faces an adverse selection problem because it only observes incomes and not productivities. Hence, taxation creates inefficiencies. Since Mirrlees (1971), the optimal tax literature has focused on labor supply as the source of such inefficiencies. This literature, however, does not capture essential aspects of labor markets. In particular, these are assumed to be perfectly competitive and unemployment only arises from a preference for leisure.

This article considers an alternative, and in our view important, source of inefficiency: Taxes alter the outcomes of the wage bargain and hence affect labor demand. In turn, labor demand has an impact on search and matching frictions and thus on unemployment. Our model is based on the search and matching literature (e.g., Mortensen and Pissarides (1999)). Firms post job vacancies and individuals choose whether to participate or not in the labor market. Those individuals who participate but fail to be matched are classified as unemployed, while those who do not participate are considered as inactive. Matching frictions create search externalities and generate rents that are shared between workers and firms through Nash-bargaining on wages. In order to focus sharply on the redistribution issue, we abstract from standard inefficiencies arising from search frictions by imposing the so-called Hosios (1990) condition ${ }^{1}$.

In the presence of redistributive taxation, a rise in the marginal tax rate implies that an increase in gross wages has a reduced impact on net wages. Therefore, it becomes less rewarding for workers to bargain aggressively and gross wages fall (see, e.g., Lockwood and Manning (1993)). This in turn increases labor demand and decreases unemployment. Such increase in labor demand is however not necessarily efficient, because a rise in employment increases both gross output and the resources absorbed to create additional vacancies. One can show that when employment is above its efficient level, a rise in labor demand decreases output net of vacancy costs. The government trades off this efficiency loss against the equity gain of higher tax revenue induced by an increase in the marginal tax rate. Hence, the optimal (i.e. second-best) wages and thus the optimal unemployment rate are below their efficient (i.e. first-best) levels.

A rise in the average tax rate leads to wage pressure and thus decreases labor demand. This can however be compensated for by an equivalent increase in the marginal tax rate. To obtain optimal wages below their efficient level, the government must set marginal tax rates above average tax rates. This implies that average tax rates are increasing through the whole distribution of productivities. Moreover, optimal marginal tax rates are positive at the top of the distribution. Since distorting employment at the top generates no equity gains, the gross wage and the employment rate of the most productive workers take their efficient values. Hence, the wage pressure at the top generated by the positive level of taxes has to be compensated for by a positive marginal tax rate.

Taxation also affects the individuals' expected gain from participating in the labor market. If the government decreases taxes on low-productivity individuals to induce them to participate, adverse selection implies that the government has to give additional informational rents to all individuals with higher productivity. This equity loss may well

\footnotetext{
${ }^{1}$ An alternative mechanism that guarantees efficiency in the economy without taxes is the competitive search framework proposed by Moen (1997).
} 
outweigh the efficiency gain of increased labor market participation. As we show, this is the case at the bottom of the productivity distribution. Hence, the government takes the lowest-productivity individuals out of the labor market by giving an assistance benefit to the inactive workers that is necessarily higher than the in-work benefit given to employed workers. As a consequence, labor market participation is below its efficient level.

Some numerical analysis illustrates the properties of the optimal tax schedule. The optimal tax schedule is almost linear. Depending on the chosen parameters, optimal marginal tax rates lie between $42 \%$ and $66 \%$. To compare these numerical results with those obtained in a Mirrlees setting, we calibrate the Mirrlees model to generate the same distribution of earnings and the same elasticity of gross earnings with respect to the marginal tax rate as our model. The results turn out to be considerably different with our recommended marginal tax rates being at least twice as high.

The way we model the impact of tax policy on labor demand is novel to the optimal tax literature. The standard Mirrlees model assumes an aggregate production function with perfect substitution between the different types of labor. Hence, hourly wages equal marginal products of labor and are independent of taxation. In such a model, taxation only affects labor supply. In particular, an increase in the marginal tax rate makes an additional working hour less rewarding in terms of additional net income. Hence, as in our model, gross income decreases. However, while in our model, the decrease in gross income emerges from the wage bargain and induces a rise in labor demand, in the Mirrlees model gross income decreases because of a decline in labor supply. Other authors have studied models where tax policy has an impact on labor demand. Stiglitz (1982) considers a two-skill model where the different types of labor are not perfect substitutes in the production function. He shows that in this case, the government's tax policy affects the hourly skill premium and thus earnings. In contrast to the wage-bargaining mechanism exposed in the present article, labor demand is affected by the production function and not by labor market frictions. Engström (2002) extends the two-skill model in a matching framework with exogenous hourly wages. As in the Mirrlees model, tax policy affects labor supply. This in turn changes the rent to be shared between the worker and the firm and hence labor demand and unemployment. The analytical framework in our paper is different since we consider fixed working hours but endogenous wages.

This paper is organized as follows. Section II presents the model and derives the analytical results. Section III is devoted to numerical simulations. In section IV, we compare the optimal schedule in our setting to the optimum in a Mirrlees-type setting. Section V concludes.

\section{The model}

We consider a static model ${ }^{2}$ where jobs differ according to their exogenous productivity denoted by $a \in\left[a_{0}, a_{1}\right]$ with $0 \leq a_{0}<a_{1} \leq+\infty$. The intensive margin of the labor supply is not taken into account here. Workers and firms are assumed to be risk neutral. Directed search is assumed for simplicity ${ }^{3}$. So, type- $a$ active workers search for type- $a$ jobs. Firms open type-specific vacancies. Each vacancy has to be filled by a single searching worker. Matching workers and vacancies is a costly activity. Following Mortensen and Pissarides

\footnotetext{
${ }^{2}$ Our static model simplifies the dynamic version of the matching model but still captures its major mechanisms (see e.g. Boone and Bovenberg (2002)).

${ }^{3}$ Since we consider the whole distribution of productivity levels, directed search seems to be a less unrealistic assumption than undirected search.
} 
(1999) and Pissarides (2000), we consider a well-behaved matching function that gives the number (measure) of type- $a$ jobs formed as a function of the number $U_{a}$ of searching workers and the number $V_{a}$ of vacancies. Employment in segment $a$ is an increasing and constant-return-to-scale function $H\left(U_{a}, V_{a}\right)$. This matching function implicitly captures heterogeneities, frictions and information imperfections on the labor market.

The size of the population is normalized to 1 . Workers' types are distributed according to a continuous density $f($.$) and a c.d.f. F($.$) . These functions are common knowledge.$ Through costly screening, the productivity of a worker is observed by the firm. We assume the government does not have this ability. The income tax system consists in a continuously differentiable non-linear tax function $T($.$) and an untaxed assistance benefit$ $b$. Since the government observes gross wages but not productivity levels, $T$ (.) conditions only on the gross wage. We assume that the job search cannot be monitored by the government. The assistance benefit $b$ is thus granted to unemployed and inactive individuals. For each type $a, w_{a}, L_{a}$ and $x_{a}$ denote respectively the gross wage (or equivalently the wage cost), the employment rate and the workers' ex-post surplus in case of employment, with $x_{a} \equiv w_{a}-T\left(w_{a}\right)-b$. Hence, type- $a$ employed workers receive $w_{a}-T\left(w_{a}\right)=x_{a}+b$. Further, we define $\Sigma_{a} \equiv x_{a} \cdot L_{a}$ as the workers' expected surplus and $Y_{a} \equiv w_{a} \cdot L_{a}$ as the workers' expected gross income. Let $d>0$ be the value of inactivity. Irrespective of their type, inactive (respectively unemployed) individuals receive $b+d$ (resp. $b$ ).

Posting a type- $a$ vacancy costs $\kappa_{a}$. This parameter captures the cost of screening applicants and the investment cost of creating a workstation. A type- $a$ filled (respectively unfilled) vacancy yields a profit of $a-w_{a}-\kappa_{a}$ (resp. $-\kappa_{a}$ ) to the firm-owner. In the literature, the vacancy cost is either taken as fixed or as proportional to productivity (see e.g. Pissarides (2000)). We therefore assume that ${ }^{4}$ :

$$
0 \leq \frac{\dot{\kappa}_{a}}{\kappa_{a}} \leq \frac{1}{a}
$$

The timing of the model is:

1. The government commits to a tax system defined as a pair $(T(), b$.$) , with T($.$) :$ $\mathbb{R}^{+} \longmapsto \mathbb{R}$ and $b \in \mathbb{R}$.

2. Firms open vacancies and workers decide whether or not to search for a job.

3. Matching occurs. Once matched, the firm and the worker negotiate the wage.

4. Transfers accrue to the agents.

This section is organized as follows. First, we deal with the objective function and the budget constraint of the government. Second, we introduce frictions and the demand side of the labor market. Third, we characterize efficiency in the idealized case where the government has perfect information on productivities. Fourth, we deal with the wage bargain. Fifth, participation and incentive constraints are defined in the case where the government observes wages but not productivities. Finally, the properties of the secondbest optimum are derived.

\footnotetext{
${ }^{4} \mathrm{~A}$ dot over a variable denotes the total derivative with respect to type $a\left(\right.$ e.g $\left.\dot{\kappa}_{a}=d \kappa_{a} / d a\right)$.
} 


\section{II.1 The government}

We first present the government's objective and its budget constraint. How productivity levels are allocated in the population is out of the scope of this article. People are simply not held responsible for their productivity. So, the government is ready to compensate for differences in productivity levels. We assume the following objective for the government:

$$
\begin{aligned}
\Omega= & \int_{a_{0}}^{a_{1}}\left\{p_{a} \cdot \Phi\left[L_{a}\left(w_{a}-T\left(w_{a}\right)\right)+\left(1-L_{a}\right) b\right]+\right. \\
& \left.\left(1-p_{a}\right) \cdot \Phi(b+d)\right\} f(a) d a
\end{aligned}
$$

where $\Phi^{\prime}()>0,. \Phi^{\prime \prime}() \leq 0,. p_{a}=1$ if type- $a$ workers participate in the labor market and $p_{a}=0$ otherwise.

This objective expresses the fact that the government cares about the distribution of expected utilities, namely $L_{a}\left(w_{a}-T\left(w_{a}\right)\right)+\left(1-L_{a}\right) b$ for those who are active and $b+d$ for inactive people. It encompasses as limiting cases the maximin criterion $(\max b)$ and the "pure" utilitarian criterion (whenever $\Phi^{\prime \prime}()=$.0 ). For expository reasons, we neglect the issue of insurance against the unemployment risk. As will soon be shown, over-employment is optimal at the second best for it contributes to the fulfillment of the incentive compatibility constraint. Under risk aversion and when insurance is incomplete, over-employment comes out for a distinct reason, namely because it enables better sharing of risks (see Hungerbühler et al. (2005)). Finally, notice that objective (2) can be microfounded if we assume that the economy is made of productivity-specific representative households that perfectly share consumption between their employed and unemployed members. From $\Sigma_{a}=L_{a}\left(w_{a}-T\left(w_{a}\right)-b\right)$, we rewrite this objective as:

$$
\Omega=\int_{a_{0}}^{a_{1}}\left\{p_{a} \cdot \Phi\left[\Sigma_{a}+b\right]+\left(1-p_{a}\right) \cdot \Phi(b+d)\right\} f(a) d a
$$

The government faces the budget constraint:

$$
\int_{a_{0}}^{a_{1}} p_{a} \cdot T\left(w_{a}\right) \cdot L_{a} \cdot f(a) d a=\left[\int_{a_{0}}^{a_{1}}\left\{p_{a}\left(1-L_{a}\right)+1-p_{a}\right\} f(a) d a\right] b+E
$$

where $E \geq 0$ is an exogenous amount of public expenditure. Since $Y_{a}-\Sigma_{a}=L_{a}\left[T\left(w_{a}\right)+b\right]$, we rewrite the government's budget constraint (4) as:

$$
\int_{a_{0}}^{a_{1}} p_{a}\left(Y_{a}-\Sigma_{a}\right) \cdot f(a) d a=b+E
$$

\section{II.2 The matching process}

Following empirical studies (see Blanchard and Diamond (1989) or Petrongolo and Pissarides (2001)), we assume a Cobb-Douglas matching function. The number of type- $a$ matches is a function of the number of type- $a$ vacancies $V_{a}$ and of the number of type- $a$ searching workers $U_{a}$ according to:

$$
H_{a}=A \cdot\left(U_{a}\right)^{\gamma} \cdot\left(V_{a}\right)^{1-\gamma} \quad \text { with } \quad \gamma \in(0,1)
$$

All type- $a$ individuals either search for a job or stay inactive. If they search, their number is $U_{a}=f(a)$. Their probability of finding a job (resp. the probability of filling a type- $a$ 
vacancy) is $L_{a}=H_{a} / U_{a}=A \cdot \theta_{a}^{1-\gamma}$ (resp. $H_{a} / V_{a}=A \cdot \theta_{a}^{-\gamma}$ ) where $\theta_{a} \equiv \frac{V_{a}}{U_{a}}$ denotes labor market tightness in the type-a segment of the labor market. An increase in the number of vacant jobs induces two types of search externalities: It increases the probability for an unemployed worker to find a job, and it diminishes the probability for a vacancy to match with a worker. Similarly, an increase in the number of workers participating in the labor market increases the probability for vacant jobs to be filled and decreases the probability for unemployed workers to match with a firm.

The expected return of posting a vacancy is $A \cdot \theta_{a}^{-\gamma} \cdot\left(a-w_{a}\right)-\kappa_{a}$. The higher the gross wage $w_{a}$, the lower this return. Firms freely enter the market and post vacancies as long as this return is positive. Therefore, in equilibrium, this return is nil (the so-called "free-entry condition"). One can then derive the type- $a$ probability of being employed (or the "labor demand"):

$$
L_{a}=A^{\frac{1}{\gamma}} \cdot\left(\frac{a-w_{a}}{\kappa_{a}}\right)^{\frac{1-\gamma}{\gamma}}
$$

The free-entry condition implies that workers' expected gross wage $w_{a} \cdot L_{a}$ equals net output (i.e. total output net of search costs $L_{a} \cdot a-\theta_{a} \cdot \kappa_{a}$ ):

$$
Y_{a}=w_{a} \cdot L_{a}=L_{a} \cdot a-\theta_{a} \cdot \kappa_{a}
$$

Taking (6) into account, we write net output under the free-entry condition as:

$$
Y_{a}\left(w_{a}\right) \equiv A^{\frac{1}{\gamma}} \cdot\left(\frac{a-w_{a}}{\kappa_{a}}\right)^{\frac{1-\gamma}{\gamma}} \cdot w_{a}
$$

\section{II.3 The first-best optimum}

In this subsection, we assume that the government perfectly observes productivities. The government chooses the assistance benefit $b$, the wage $w_{a}$, the participation indicator $p_{a}$ and workers' expected surplus $\Sigma_{a}$ to maximize the social objective (3) subject to the budget constraint (5) and the labor demand (6):

$$
\begin{aligned}
& \max _{w_{a}, p_{a}, \Sigma_{a}, b} \int_{a_{0}}^{a_{1}}\left\{p_{a} \cdot \Phi\left[\Sigma_{a}+b\right]+\left(1-p_{a}\right) \cdot \Phi(b+d)\right\} f(a) d a \\
& \text { s.t: } \quad \int_{a_{0}}^{a_{1}} p_{a}\left(Y_{a}\left(w_{a}\right)-\Sigma_{a}\right) \cdot f(a) d a=b+E
\end{aligned}
$$

As shown in appendix A, the solution to this problem implies the following results. First, $\Sigma_{a}^{*}=d$ for all participating types. Hence, agents' expected utility is equated across participation/non-participation states and productivity types. Second, the first-best gross wage $w_{a}^{*}$ maximizes net output. Efficient (i.e. net output-maximizing) values of gross wages, employment, and net output are:

$$
\begin{aligned}
& w_{a}^{*}=\gamma \cdot a \quad, \quad L_{a}^{*}=(1-\gamma)^{\frac{1-\gamma}{\gamma}} \cdot A^{\frac{1}{\gamma}} \cdot\left(\frac{a}{\kappa_{a}}\right)^{\frac{1-\gamma}{\gamma}} \\
& Y_{a}^{*}=Y_{a}\left(w_{a}^{*}\right)=\gamma(1-\gamma)^{\frac{1-\gamma}{\gamma}} \cdot A^{\frac{1}{\gamma}} \cdot a \cdot\left(\frac{a}{\kappa_{a}}\right)^{\frac{1-\gamma}{\gamma}}
\end{aligned}
$$

To increase employment above $L_{a}^{*}$, firms have to open more vacancies. The resources spent on creating these vacancies are not offset by the increase in output. Matching frictions 
therefore imply that full employment is not efficient ${ }^{5}$. Equations (1) and (9) imply that the efficient level of employment is non-decreasing in $a$. Finally, let $a_{d}^{*}$ be defined by:

$$
Y_{a_{d}^{*} \geq}^{*}=d \quad \text { if } \quad a_{d}^{*} \stackrel{>}{=} a_{0}
$$

The efficient participation condition implies that every type above (below) $a_{d}^{*}$ participates (stays inactive).

\section{II.4 The wage bargain}

We henceforth consider the case where the government does not observe productivities. Therefore, the tax schedule $T($.$) is a function of gross wages only. Once a firm and a$ worker are matched, they bargain over the wage. In the absence of an agreement, nothing is produced and the worker gets the assistance benefit $b$. These outside options imply the existence of a positive rent $a-T\left(w_{a}\right)-b$. As is standard in the literature (see Pissarides $(2000)$ ), this rent is shared by maximizing a Nash product. The wage $w_{a}$ maximizes the Nash product depending on the worker's and the firm's surplus if they reach an agreement:

$$
\max _{w_{a}}\left[w_{a}-T\left(w_{a}\right)-b\right]^{\beta} \cdot\left[a-w_{a}\right]^{1-\beta}
$$

taking $b$ and $T($.$) as given and where \beta \in(0,1)$ denotes the worker's bargaining power. For convenience, we redefine the Nash product as:

$$
\max _{w_{a}}\left[w_{a}-T\left(w_{a}\right)-b\right] \cdot A^{\frac{1}{\gamma}} \cdot\left[a-w_{a}\right]^{\frac{1-\beta}{\beta}}
$$

From Equation (6), workers' expected surpluses coincide with the (redefined) Nash products if, as we henceforth assume, the Hosios condition $\beta=\gamma$ is fulfilled. This condition states that the relative weight of the firm's surplus in the Nash product $(1-\beta) / \beta$ is equal to the elasticity of labor demand with respect to the firm's surplus $(1-\gamma) / \gamma$. Under the Hosios condition, efficiency is reached in the absence of taxes and benefits. The results of this paper would therefore also be obtained in the case of any other wage setting that maximizes workers' expected utility $\Sigma_{a}+b$, given the labor demand function (6) and the tax system $(T(), b$.$) . This is in particular the case with skill-specific monopoly unions.$ Henceforth, $\Sigma_{a}$ will denote both the workers' expected surplus evaluated at bargained wages and the maximised Nash product:

$$
\Sigma_{a}=\max _{w_{a}} \quad\left[w_{a}-T\left(w_{a}\right)-b\right] \cdot A^{\frac{1}{\gamma}} \cdot\left[\frac{a-w_{a}}{\kappa_{a}}\right]^{\frac{1-\gamma}{\gamma}}
$$

The first-order condition leads to:

$$
w_{a}=\frac{\gamma\left(1-T_{a}^{\prime}\right) a+(1-\gamma)\left(T_{a}+b\right)}{\gamma\left(1-T_{a}^{\prime}\right)+1-\gamma}
$$

where $T_{a}^{\prime} \equiv T^{\prime}\left(w_{a}\right)$ denotes the marginal tax rate and $T_{a} \equiv T\left(w_{a}\right)$ denotes the level of taxes for a type- $a$ worker. Furthermore, the first-order condition of (11) implies:

$$
\frac{w_{a}}{a-w_{a}}=\frac{\gamma}{1-\gamma} \cdot \frac{1-T_{a}^{\prime}}{1-\frac{T_{a}+b}{w_{a}}}
$$

\footnotetext{
${ }^{5} A$ and $\kappa_{a}$ are assumed to be such that $L_{a}^{*}<1$ and $a-w_{a}^{*}>\kappa_{a}$.
} 
Since neither the firms' nor the workers' ex-post surplus can be negative, we conclude that:

$$
T_{a}^{\prime} \leq 1
$$

Therefore, the worker's ex-post surplus $x_{a}=w_{a}-T\left(w_{a}\right)-b$ is necessarily an increasing function of the gross wage $w_{a}$.

In the rest of this subsection, we consider the level of tax $T_{a}$ and the marginal tax rate $T_{a}^{\prime}$ as parameters. The tax schedule influences the labor market equilibrium in two ways. First, higher levels of taxes $T_{a}$ (or benefits $b$ ) reduce the workers' ex-post surplus. Therefore, workers claim higher wages. This positive effect on individual gross earnings is similar to what occurs in a labor supply framework when leisure is a normal good. There, a rise in the level of taxes at given marginal tax rates increases labor supply. Here this upward pressure on wages reduces employment.

Second, keeping $T_{a}$ constant, the wage is decreasing in the marginal tax rate $T_{a}^{\prime}$ because a unit rise in the gross wage increases net earnings at a rate of one minus the marginal tax rate. As the marginal tax rate rises, workers earn less from each increase in gross wages while the effect on firms' profits remains unchanged. Therefore, workers have fewer incentives to claim higher wages (see Malcomson and Sartor (1987), Lockwood and Manning (1993), Holmlund and Kolm (1995), Pissarides (1998), Sørensen (1999) or Boone and Bovenberg (2002) among others). As in a labor supply framework, higher marginal tax rates decrease individual gross earnings. However, in the labor supply literature, the channel is different because there gross earnings are decreasing due to lower working hours. Here, labor demand rises.

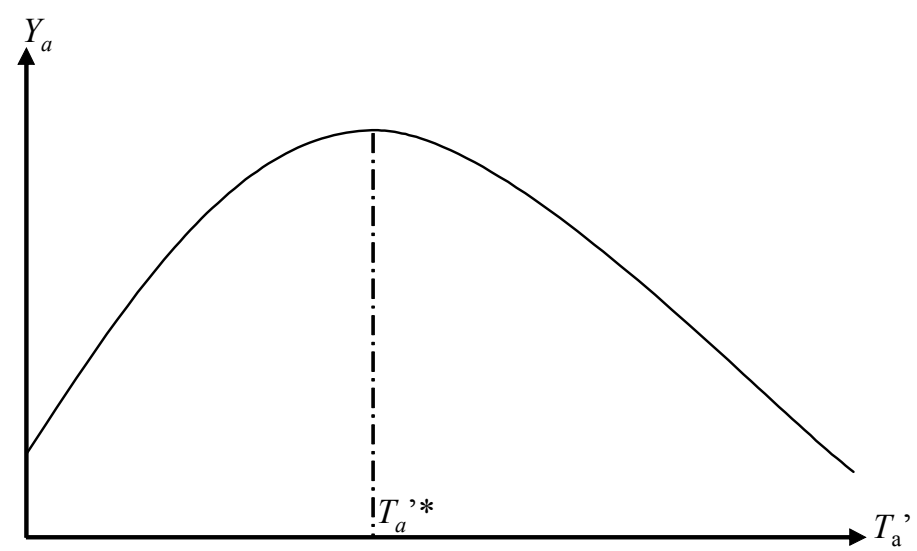

Figure 1: The impact of the marginal tax rate $T_{a}^{\prime}$ on efficiency at a given level of taxes $T_{a}$.

A rise in $T_{a}^{\prime}$ at a given tax level $T_{a}$ has a non-monotonic effect on net output $Y_{a}$. The gross wage $w_{a}$ decreases according to Equation (12). So, employment $L_{a}$ and therefore gross output $a \cdot L_{a}$ and total vacancy costs $\kappa_{a} \cdot \theta_{a}$ increase. When the wage level is higher (respectively lower) than its efficient value $w_{a}^{*}$, the effect on gross output (resp. on vacancy costs) dominates, so net output increases (resp. decreases). The relationship between net output and the marginal tax rate is therefore hump shaped (see Figure 1). Let the "efficient marginal tax rate" $T_{a}^{*}$ be the one that maximizes net output for a given 
level of tax. From Equations (9) and (13):

$$
T_{a}^{*}=\frac{T_{a}+b}{\gamma \cdot a}=\frac{T_{a}+b}{w_{a}^{*}}
$$

This equality establishes an upward relationship between the efficient marginal tax rate and the level of taxes.

\section{II.5 Participation and incentive constraints}

A worker decides to search as long as the expected utility when searching, $\Sigma_{a}+b$, is higher than the assistance benefit $b$ plus the value of inactivity $d$. The participation constraint can then be written as:

$$
\Sigma_{a} \geq d
$$

Applying the envelope theorem to Equation (11), we get:

$$
\dot{\Sigma}_{a}=\frac{1-\gamma}{\gamma}\left(\frac{1}{a-w_{a}}-\frac{\dot{\kappa}_{a}}{\kappa_{a}}\right) \Sigma_{a}
$$

Equations (1) and (16) imply that the maximized Nash product or equivalently the expected worker's surplus, $\Sigma_{a}$, is increasing in productivity. Therefore, there exists a single threshold $a_{d} \geq a_{0}$ such that workers endowed with $a<a_{d}$ stay inactive whereas workers with $a \geq a_{d}$ search for a job.

The strategic interaction between the firm and the worker is modelled in a reduced form way. Given a tax system $(T(), b$.$) , the worker-firm pair chooses the wage that maximizes$ the Nash product ${ }^{6}$. Any tax system thus induces a four tuple $\left(a_{d},\left\{w_{a}, x_{a}, \Sigma_{a}\right\}_{a \in\left[a_{d}, a_{1}\right]}\right)$, where $\forall a \in\left[a_{d}, a_{1}\right]$ :

$$
\begin{gathered}
w_{a}=\arg \max _{w_{\hat{a}}}\left[w_{\hat{a}}-T\left(w_{\hat{a}}\right)-b\right] \cdot A^{\frac{1}{\gamma}} \cdot\left[\frac{a-w_{\hat{a}}}{\kappa_{a}}\right]^{\frac{1-\gamma}{\gamma}} \\
x_{a}=w_{a}-T\left(w_{a}\right)-b \\
\Sigma_{a}=\left[w_{a}-T\left(w_{a}\right)-b\right] \cdot A^{\frac{1}{\gamma}} \cdot\left[\frac{a-w_{a}}{\kappa_{a}}\right]^{\frac{1-\gamma}{\gamma}} \\
\Sigma_{a_{d}}=d
\end{gathered}
$$

The government can be modeled as selecting a tax system $(T(), b$.$) and tuple \left(a_{d},\left\{w_{a}, x_{a}, \Sigma_{a}\right\}_{a \in\left[a_{d}, a_{1}\right]}\right)$ subject to these constraints. Equivalently, the government can be modelled as choosing the tuple $\left(a_{d},\left\{w_{a}, x_{a}, \Sigma_{a}\right\}_{a \in\left[a_{d}, a_{1}\right]}\right)$ directly subject to the incentive compatibility constraint:

$$
\Sigma_{a}=x_{a} \cdot A^{\frac{1}{\gamma}} \cdot\left[\frac{a-w_{a}}{\kappa_{a}}\right]^{\frac{1-\gamma}{\gamma}} \geq x_{\hat{a}} \cdot A^{\frac{1}{\gamma}} \cdot\left[\frac{a-w_{\hat{a}}}{\kappa_{a}}\right]^{\frac{1-\gamma}{\gamma}} \quad \forall a, \tilde{a} \in\left[a_{d}, a_{1}\right]
$$

and the participation constraint $\Sigma_{a_{d}} \geq d$. This equivalence comes from the fact that any allocation available to the government in the first problem is available to it in a game in

\footnotetext{
${ }^{6}$ We assume that earnings are perfectly and costlessly observed. Tax evasion is therefore neglected and side-payments are not allowed.
} 
which it selects a direct mechanism and then a worker-firm pair selects a report ${ }^{7}$. This equivalence result is commonly known as the "taxation principle" (see Hammond (1979) and Guesnerie (1995)). By the revelation principle, attention can then be restricted to equilibria that entail truth telling.

Standard principal-agent techniques then apply (see Salanie (1997) and Laffont and Martimort (2002)). The Nash product can be written as a function $N(a, w, x)$ of the type $a$, the gross wage $w$ and the worker's ex-post surplus $x$ in the following way:

$$
N(a, w, x) \equiv A^{\frac{1}{\gamma}}\left(\frac{a-w}{\kappa_{a}}\right)^{\frac{1-\gamma}{\gamma}} x
$$

The worker's surplus $x$ has to increase when the gross wage $w$ increases to keep the Nash product $N(a, .,$.$) unchanged. For each pair (w, x)$ the marginal rate of substitution:

$$
\left.\frac{\partial x}{\partial w}\right|_{N(a, . .)}=\frac{1-\gamma}{\gamma} \frac{x}{a-w}
$$

is a decreasing function of the type $a$. This single-crossing property is illustrated in Figure 2 that displays the indifference curves in terms of the Nash product $N(a, .,$.$) for worker-$ firm combinations with different productivity levels $a^{\prime}>a$. The higher the productivity of a match, the less elastic is the firm's surplus to the gross wage and the less sensitive is the Nash product to changes in the gross wage. Given the single crossing property, the incentive compatibility constraint (17) is equivalent to the first order condition (16) and the second-order condition which are (see appendix B.1):

$$
\forall a \in\left[a_{d}, a_{1}\right] \quad \dot{\Sigma}_{a}=\frac{1-\gamma}{\gamma}\left(\frac{1}{a-w_{a}}-\frac{\dot{\kappa}_{a}}{\kappa_{a}}\right) \Sigma_{a} \quad \text { and } \quad \dot{w}_{a}>0
$$

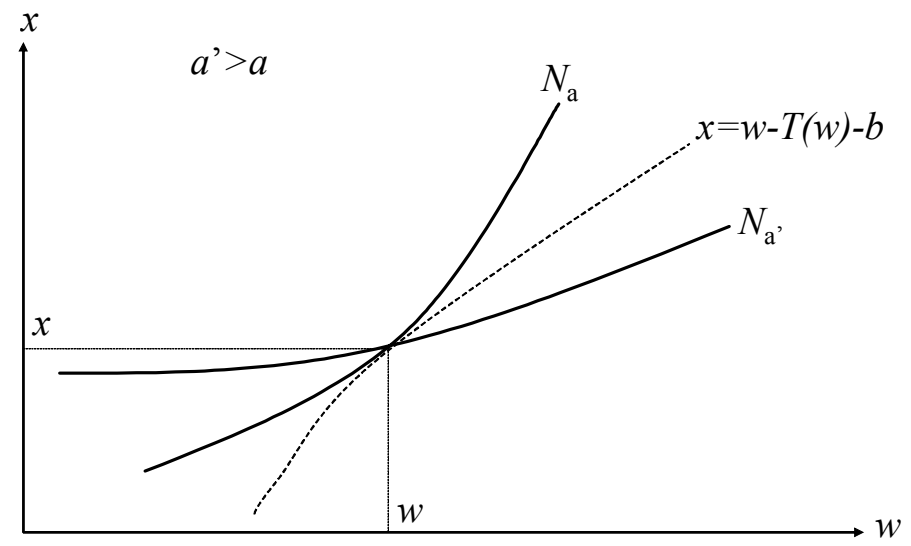

Figure 2: The single-crossing property.

\footnotetext{
${ }^{7}$ The rewriting described above shows the equivalence of the tax function to a class of direct mechanisms. The latter mechanisms basically treat the worker and the firm as a single agent with preferences described by the Nash bargain objective. There may be other mechanisms available to the government that exploit the fact that the firm and the worker are different and that deliver a better outcome (see e.g. Cremer and McLean (1988)). However, they are not considered here.
} 


\section{II.6 The second-best optimum}

Under asymmetric information, the government chooses the threshold $a_{d}$, the assistance benefit $b$, the wage and the workers' expected surplus functions $\left(w_{a}, \Sigma_{a}\right)$ to maximize the government's objective (3) subject to the budget constraint (5), the labor demand (6), the participation constraints (15) and the incentive constraints $(16)^{8}$. The program of the government is therefore:

$$
\begin{gathered}
\max _{a_{d}, w_{a}, \Sigma_{a}, b} F\left(a_{d}\right) \Phi(b+d)+\int_{a_{d}}^{a_{1}} \Phi\left(\Sigma_{a}+b\right) f(a) d a \\
\text { s.t. : } \int_{a_{d}}^{a_{1}}\left(Y_{a}\left(w_{a}\right)-\Sigma_{a}\right) \cdot f(a) d a=b+E \\
\dot{\Sigma}_{a}=\frac{1-\gamma}{\gamma}\left(\frac{1}{a-w_{a}}-\frac{\dot{\kappa}_{a}}{\kappa_{a}}\right) \Sigma_{a} \quad\left\{\begin{array}{l}
\Sigma_{a_{d}}=d \\
\Sigma_{a_{d}} \geq d
\end{array} \text { if } \quad \begin{array}{l}
a_{d}>a_{0} \\
a_{d}=a_{0}
\end{array}\right.
\end{gathered}
$$

For any value of $a_{d}$ and $b$, this is a standard optimal control problem where workers' expected surplus $\Sigma_{a}$ is the state variable and the gross wage $w_{a}$ is the control variable. The first-order conditions lead to the following formulation of the equity-efficiency trade-off for all $a \geq a_{d}$ (see Appendix B.2):

$$
\lambda \cdot \frac{\partial Y_{a}}{\partial w_{a}} \cdot f(a)=\frac{1-\gamma}{\gamma\left(a-w_{a}\right)^{2}} \int_{a}^{a_{1}}\left\{\lambda-\Phi_{t}^{\prime}\right\} \Sigma_{t} \cdot f(t) \cdot d t
$$

where $\lambda$ is the Lagrange multiplier associated with the budget constraint and $\Phi_{a}^{\prime} \equiv$ $\Phi^{\prime}\left(\Sigma_{a}+b\right)$. For $a<a_{d}$, we define $\Phi_{a}^{\prime} \equiv \Phi^{\prime}(b+d)$.

Consider a marginal increase in the type- $a$ wage. The maximized Nash product achieved by type- $a$ worker-firm combinations, $\Sigma_{a}$, is fixed by the incentive constraints for less productive pairs. The rise in the wage decreases the employment level $L_{a}$ and thereby gross output $L_{a} \cdot a$ but also the resources spent on posting vacancies. The effect on net output $Y_{a}$ is therefore ambiguous. If $w_{a}<w_{a}^{*}$ (resp. $>$ ), this effect is positive (resp. negative). Multiplying this by the number of type- $a$ agents $f(a)$ and the shadow cost of public funds $\lambda$, the left-hand side of (19) measures the social value of the net marginal change in output. This captures the efficiency side of the trade-off.

The right-hand side of (19) represents the equity cost of a higher gross wage for type- $a$ worker-firm combinations. As $w_{a}$ rises at fixed $\Sigma_{a}$, more productive worker-firm pairs find it more attractive to mimic type- $a$ combinations. To prevent this, the Nash product accruing to the former has to grow. Looking at Equation (16), the term in front of the integral on the right-hand side of (19) measures by how much the rate of change of the maximized Nash product $\dot{\Sigma}_{a} / \Sigma_{a}$ has to grow when $w_{a}$ marginally increases. The incentive compatibility constraints will remain satisfied if all combinations with a productivity higher than $a$ benefit from an equivalent relative increase in their Nash product. For any type $t$ above $a$, this relative increase times $\Sigma_{t}$ gives the rise in the Nash product. Each unit of the latter generates an increase in the social welfare measured by $\Phi_{t}^{\prime}$ and implies a budgetary cost equal to $\lambda$.

The proof of the following normative properties is set out in the appendices.

Proposition 1 The optimal levels of the gross wage and employment are efficient at the top of the distribution.

\footnotetext{
${ }^{8}$ Throughout the paper, we consider only the first-order incentive constraint and verify ex-post in our simulations that $\dot{w}_{a}>0$.
} 
The right-hand side of (19) indicates that changing the gross wage at the top has no distributional effect. The government can therefore set this gross wage at the level $w_{a_{1}}^{*}$ which maximizes net output.

Proposition 2 For all worker-firm pairs with productivity $a_{d} \leq a<a_{1}$, the optimal gross wages are below their efficient levels $w_{a}^{*}$ and the optimal employment levels are above their efficient levels $L_{a}^{*}$.

Consider that the tax schedule has been optimized for all workers up to type $a$. The maximized Nash product of type- $a$ worker-firm combinations, $\Sigma_{a}$, is predetermined by the incentive compatibility constraints. This level of the Nash product is depicted in Figure 3 by the curve denoted $\Sigma_{a}$. Let $w_{a}$ decrease below its efficient value $w_{a}^{*}$. This only has a second-order effect on efficiency. But there is a first-order effect on the Nash products and thus on workers' expected surplus $\Sigma_{\tilde{a}}$ for types $\tilde{a}>a$. By reducing $w_{a}$, the government can reduce the latter (see Equation (16) and the downward shift of the curve labeled $\Sigma_{\tilde{a}}$ in Figure 3). The government can extract more tax revenues from these types above $a$. This gain in resources is valued at the marginal cost of public funds $\lambda$. The loss in the workers' expected surplus for these types is valued at the marginal social welfare $\Phi_{\tilde{a}}^{\prime}, \tilde{a}>a$. Following Equation (19), these two effects are integrated over all types above $a$. Since the assistance benefit is optimally chosen, the property $\int_{a_{0}}^{a_{1}}\left(\Phi_{t}^{\prime}-\lambda\right) f(t) d t=0$ holds (see Equation (28) in appendix B.2). As $\Sigma_{a}$ is increasing in $a, \Phi_{a}^{\prime}$ is decreasing in $a$, and the right-hand side of (19) is therefore always positive. In other words, the additional tax revenues are more valued than the loss in utility above $a$. Therefore the optimal value of $w_{a}$ should be below its efficient level.

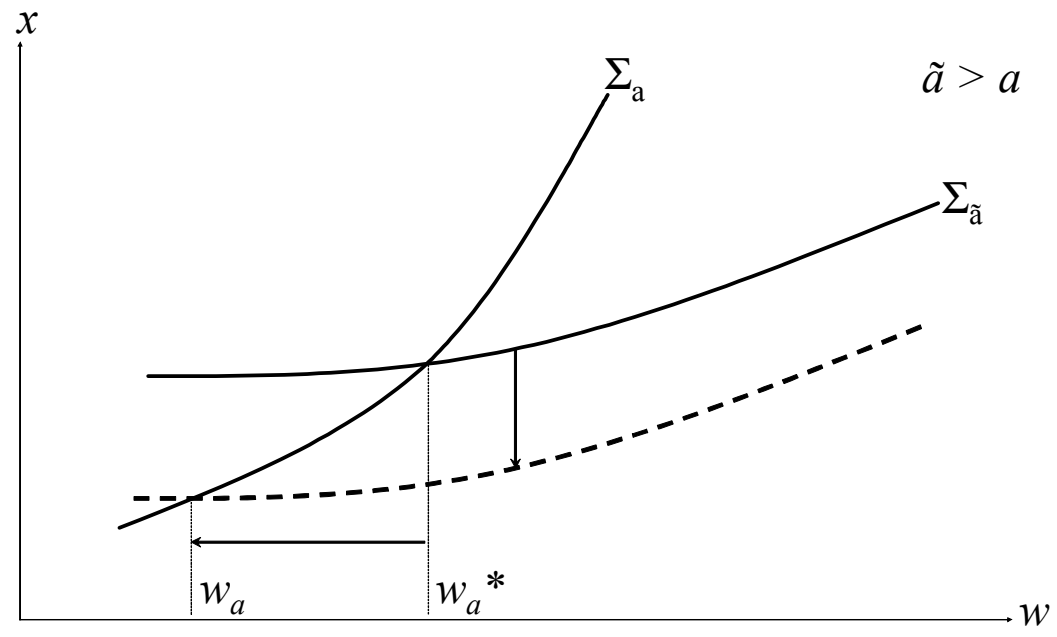

Figure 3: The equity-efficiency trade-off.

Another intuition for Proposition 2 is given by Figure 1. Keeping the level of taxes unchanged up to $T_{a}$, a rise in the marginal tax $T_{a}^{\prime}$ creates an equity gain since it enables the government to tax richer workers more heavily. At the optimum, this equity gain has to be compensated for by a loss in efficiency. According to Figure 1, the marginal tax rate is then necessarily higher than the efficient one. Consequently, the wage rate is below its efficient level and therefore there is over-employment. So, as in the standard optimal 
income taxation model, incentive constraints lead to a decline in gross earnings. However, this reduction here implies a rise in labor demand, whereas in the standard optimal income taxation literature it follows from a reduction in labor supply.

Proposition 2 recommends over-employment for all participating types (except at the top of the productivity distribution). Many are convinced that there actually is underemployment, in particular at medium and low productivity levels. Adopting this view, Proposition 2 has to be considered in a normative way. As the underlying model is highly stylized, this result should be considered with care. The main message is that endogenizing wages and labor demand leads to recommending a fiscal stimulation of labor demands for participating types. The next proposition deals with the adverse effect of this stimulation on the optimal participation rate.

Proposition 3 The optimal participation rate is lower than or equal to its efficient value.

Aggregate net output and hence efficiency increase if individuals of types $a \in\left[a_{d}^{*}, a_{d}\right)$ participate. But their participation also gives to worker-firm pairs with productivity above $a_{d}$ the possibility of mimicking them. To avoid this mimicking, the government has to give an additional informational rent to these more productive matches. If this equity cost is higher than the efficiency gain, the government prefers that individuals of types $a \in\left[a_{d}^{*}, a_{d}\right)$ do not participate.

Combining Propositions 2 and 3, the efficient and the second-best optimal levels of total employment $L=\int_{a_{0}}^{a_{1}} L_{a} f(a) d a$ cannot be ranked. On the one hand, fewer people participate in the labor market. On the other hand, more participants are employed.

Proposition 4 In-work benefits (if any) are lower than assistance benefits.

An in-work benefit (i.e. $\left.-T\left(w_{a_{d}}\right)\right)$ that is higher than assistance benefits increases participation. However, proposition 3 shows that the government chooses not to increase participation. This proposition implies that an EITC (as defined by Saez (2002)) would not be optimal at the second best.

Proposition 5 Optimal average tax rates are increasing with the wage level. Optimal marginal tax rates are positive everywhere.

To decentralize an optimum where wages are below their efficient values, optimal marginal tax rates are higher than the average tax rates at each point of the wage distribution (see Equation (13)). This has two striking consequences: optimal average tax rates are increasing through the whole distribution and optimal marginal tax rates are positive, even at the top of the distribution.

The first part of proposition 5 should be stressed, since standard optimal income taxation models with endogenous labor supply do not yield precise analytical results about the shape of average tax rates. With a bounded distribution of productivity, this literature has shown that the optimal marginal tax rate equals zero at the top. Therefore, one only knows that the optimal average tax rate is necessarily decreasing close to the top of the distribution.

Since the value of inactivity is unique, the second part of Proposition 5 is in accordance with the standard optimal income taxation models, except at the top of the distribution. The reason why the optimal marginal tax rate is positive at the top in our model is easily understood. As the government wants to redistribute income in favor of less productive 
agents, the level of taxes is positive at the top. This distorts the gross wage upwards. To restore an efficient wage level (Proposition 1), a positive marginal tax rate is therefore needed at the top (see Equation (14)). To produce positive marginal tax rates at the top of the distribution, the standard optimal income taxation literature needs specific assumptions such as an unbounded Pareto distribution of productivities (Diamond 1998 and Saez 2001).

There are no analytical results about the profile of marginal tax rates. If the levels of wages and of employment were efficient everywhere, the upward profile of average tax rates would require a rising profile of marginal tax rates according to Equation (14). However, Proposition 2 implies that there is over-employment everywhere, except at the top. Marginal taxes are therefore higher than their efficient values. From Propositions 1 and 2 , one knows that the positive difference between optimal and efficient employment levels has to decline with productivity levels in the neighborhood of the top of the distribution. We do not know more. So, possible changes in the intensity of the over-employment effect could lead to a non-monotonic relationship between marginal tax rates and wages.

\section{Simulations}

\section{III.1 Calibration}

The parameters are chosen to roughly represent key figures for France. For the productivity distribution, we use a truncated log-normal density function ${ }^{9}$ :

$$
f(a)=\frac{K}{a} \exp \left[-\frac{1}{2}\left(\frac{\log a-\log \left(\mu \cdot a_{1}+(1-\mu) a_{0}\right)}{\xi}\right)^{2}\right]
$$

where $K$ is a scale parameter. $\mu$ and $\xi$ are calibrated using the monthly wages of full time working individuals found in the French Labor Force Survey 2002 (Enquête Emploi) ${ }^{10}$, which gives $\xi=0.4$ and $\mu=0.2$. The lower bound of the productivity distribution, $a_{0}$ is set at 0 and the distribution is truncated at $a_{1}=20000$ Euros. The distribution of $a$ in the benchmark case is displayed in solid lines in Figure 4.

According to the empirical literature (see Petrongolo and Pissarides (2001)), the elasticity of the matching function, $\gamma$, is set at 0.5 . The Hosios condition then implies that the worker and the firm have equal bargaining power. There is no micro-evidence available for the values of the vacancy costs $\kappa_{a}$ and the scale parameter of the matching function, $A$. We calibrate these values to obtain unemployment rates of $2 \%$ at the top and $25 \%$ at the bottom in the economy without taxes. Assuming an iso-elastic shape so that $\kappa_{a} \cdot A^{\frac{1}{\gamma-1}}=\kappa_{0} \cdot a^{l}$, we get $\kappa_{0}=0.62$ and $l=0.88$. Similarly, there is no clear evidence on the value of leisure. We take a value of leisure $d$ of 500 euros in the benchmark case and conduct thereafter sensivity analyses with respect to this parameter. To keep things simple, public expenditure $E$ is set equal to zero. Finally, the government's utility function is assumed to be a CES function of the expected utility, i.e. $\Phi(\Omega)=\Omega^{1-\sigma} /(1-\sigma)$. A

\footnotetext{
${ }^{9}$ This form used to be typical in the literature (Mirrlees (1971), Tuomola (1990) and Boadway et al. (2000); see Diamond (1998) and Saez (2001) for a critique).

${ }^{10}$ To keep things simple, we approximate the actual tax system by considering that $\left(1-T_{a}^{\prime}\right) /\left(1-\frac{T_{a}+b}{w_{a}}\right)$ is constant, which is in line with the data from the OECD tax database. Unobserved productivity levels $a$ are then proportional to gross wages $w_{a}$ (see. Equation (13)). Hence, $\mu$ and $\xi$ are the same for both the wage and productivity distributions. A sensitivity analysis with respect to the productivity distribution will be conducted in subsection III.3.4.
} 


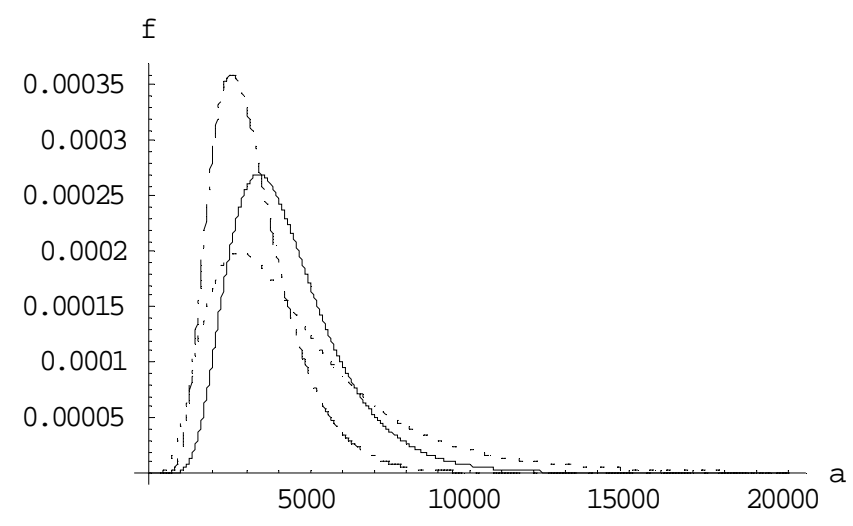

Figure 4: Density Functions $f(a)$. The benchmark case is the solid line. A dotted line is used for $(\mu, \xi)=(0.2 ; 0.6)$ and a dashed line for $(\mu, \xi)=(0.15 ; 0.4)$.

\begin{tabular}{|c|c|c|c|c|c|}
\hline$\sigma$ & $\gamma$ & $d$ & $\mu$ & $\xi$ & $E$ \\
\hline 1 & 0.5 & 500 & 0.2 & 0.4 & 0 \\
\hline
\end{tabular}

Table 1: Parameter values in the benchmark case.

government that is more concerned about redistribution will be characterized by a higher value of $\sigma$. If a type $a$ has an expected utility $N$ times that of a type $a^{\prime}$, the social value of a marginal increase in expected utility is $N^{\sigma}$ higher for type $a^{\prime}$ compared to $a$. In the benchmark case, we take $\sigma$ equal to 1 ( $\operatorname{so} \Phi(\Omega)=\log (\Omega)$ ). Table 1 summarizes the values of the parameters.

\section{III.2 The benchmark}

As expected from Propositions 1 and 2, employment is above its efficient level for all participating types $a \geq a_{d}$, except at the top of the distribution ${ }^{11}$. As shown in Figure 5 , over-employment is more pronounced for low productivity levels. This property is not surprising. As in the Mirrlees setting, our model predicts that the government should highly distort the outcomes of the low productivity types because there are few of them. The corresponding marginal tax rates should therefore be high. However, introducing a continuous extensive labor supply margin might remove this property. In Saez (2002), marginal tax rates can become negative if participation elasticities are sufficiently high. Similarly, Boone and Bovenberg $(2004,2005)$ show that the introduction of search costs might also lead to negative marginal tax rates. At the bottom of the distribution, such decreases in marginal tax rates could attenuate the over-employment property of our optimum.

In line with Proposition 3, the participation rate of $94 \%$ is below its level in the economy without taxes (see Table 2). Combining this result with the previously mentioned overemployment property for participating types, the net effect of these opposing forces is that total optimal employment $L=\int_{a_{0}}^{a_{1}} L_{a} f(a) d a$ is $1.8 \%$ above its level in the economy without taxes (see Table 2).

As depicted by the solid lines in Figure 6, the optimal tax function turns out to be

\footnotetext{
${ }^{11}$ The simulation programs are available on http://www.u-paris2.fr/ermes/membres/lehmann/lehmann.htm
} 


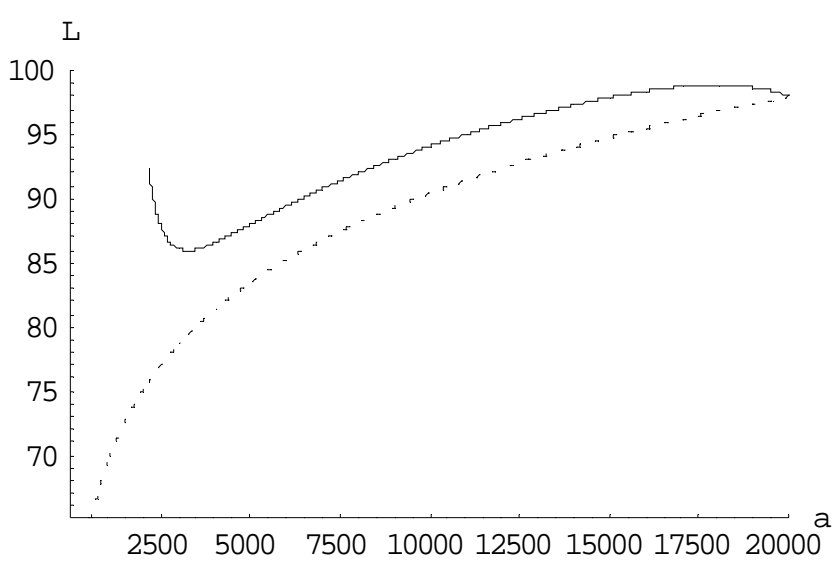

Figure 5: Employment levels in the benchmark case. Solid lines for the optimum. Dotted lines for the economy without taxes.

close to linear. Marginal tax rates are first decreasing and then slightly hump-shaped. They lie between $52 \%$ and $59 \%$. The optimal level of assistance benefit is quite high at 809 Euros per month.

\section{III.3 Sensitivity analysis}

\section{III.3.1 The aversion to inequality}

When the aversion to inequality, $\sigma$, is doubled, the government puts more emphasis on redistribution in the equity-efficiency trade-off. Hence, wages are more downwards distorted and marginal tax rates shift upwards by about 5 percentage points (see Figure 6 ). The assistance benefit varies slightly. Since the benchmark already leads to a high degree of redistribution, these changes in the tax system are rather small. Table 2 shows the effect of the government's preference for redistribution on total employment. On the one hand, an increase in $\sigma$ decreases the participation rate. On the other hand, the higher amount of redistribution increases employment distortions for the participating types. The net effect on total employment is thus ambiguous.
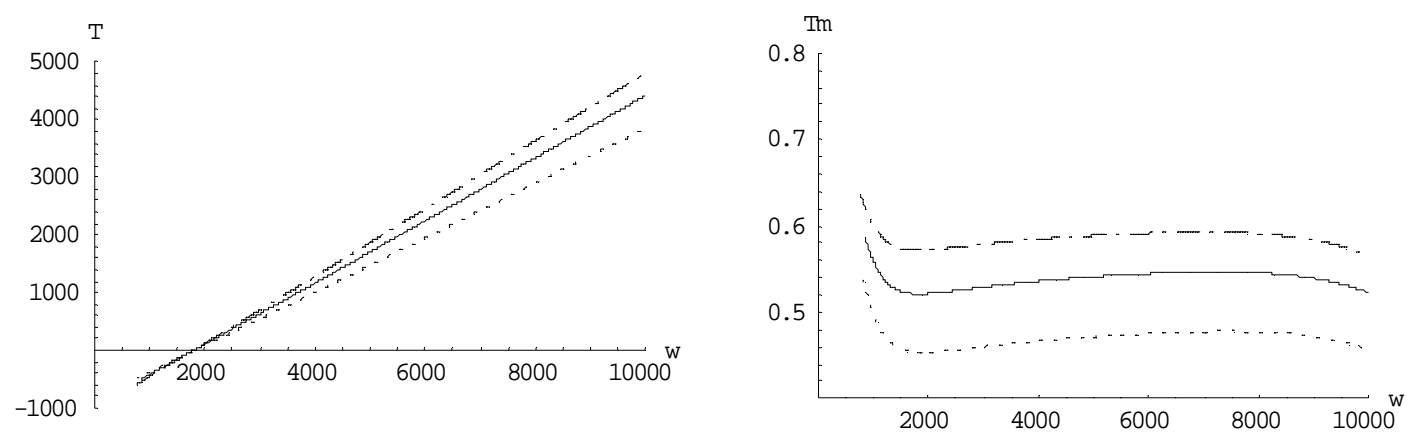

Figure 6: Dotted, solid and dashed lines respectively for $\sigma$ equal to $0.5,1$ and 2. 


\begin{tabular}{|c|ccc|c|ccc|}
\hline & \multicolumn{3}{|c|}{ Employment $L$} & $b$ & \multicolumn{3}{|c|}{ Participation } \\
& WT & SB & $\Delta$ & & WT & SB & $\Delta$ \\
\hline \hline Benchmark & 81.1 & 82.6 & $+1.8 \%$ & 809 & 99.6 & 94.0 & -5.6 \\
\hline \hline$\sigma=0.5$ & 81.1 & 82.7 & $+1.9 \%$ & 722 & 99.6 & 95.9 & -3.7 \\
\hline$\sigma=2.0$ & 81.1 & 84.8 & $+4.6 \%$ & 853 & 99.6 & 93.7 & -5.9 \\
\hline \hline$d=300$ & 81.4 & 84.6 & $+3.9 \%$ & 1070 & 100.0 & 98.3 & -1.7 \\
\hline$d=700$ & 78.3 & 80.1 & $+1.0 \%$ & 575 & 97.1 & 89.4 & -7.7 \\
\hline \hline$\gamma=0.4$ & 80.2 & 82.0 & $+2.2 \%$ & 511 & 98.4 & 91.5 & -6.9 \\
\hline$\gamma=0.6$ & 81.3 & 84.1 & $+3.4 \%$ & 1090 & 99.9 & 96.8 & -3.1 \\
\hline \hline$\xi=0.6$ & 78.7 & 79.5 & $+1.1 \%$ & 960 & 96.1 & 85.6 & -10.5 \\
\hline \hline$\mu=0.15$ & 76.8 & 77.1 & $+0.5 \%$ & 430 & 97.3 & 89.2 & -8.1 \\
\hline \hline$\frac{E}{Y^{*}}=0.2$ & 81.1 & 84.6 & $+4.3 \%$ & 445 & 99.6 & 95.0 & -4.6 \\
\hline
\end{tabular}

Table 2: Numerical results. WT stands for the economy without taxes and SB stands for the second best. $Y^{*}$ denotes aggregate efficient net output in an economy without taxes, i.e. $Y^{*}=\int_{a_{d}^{*}}^{a_{1}} Y_{a}^{*} f(a) d a$.

\section{III.3.2 The value of inactivity}

Consider a rise in the value of inactivity $d$. If the expected surplus $\Sigma_{a}$ remained unchanged along the whole distribution, fewer individuals would participate in the labor market. So the budget of the government would not be balanced anymore. Two types of adjustments could restore the equality between expenses and receipts. First, the level of the assistance benefit $b$ could decrease. Second, the decline in participation could be attenuated. The latter adjustment takes place if the expected surplus $\Sigma_{a}$ rises. This means that the government gives more informational rents to active workers. As illustrated by Figure 3, wages are then less distorted. Consequently, marginal tax rates decline. As can be seen in Table 2 and Figure 7, as $d$ increases, the optimal mix between efficiency and equity requires that both adjustments take place: Marginal tax rates and the assistance benefit are reduced.
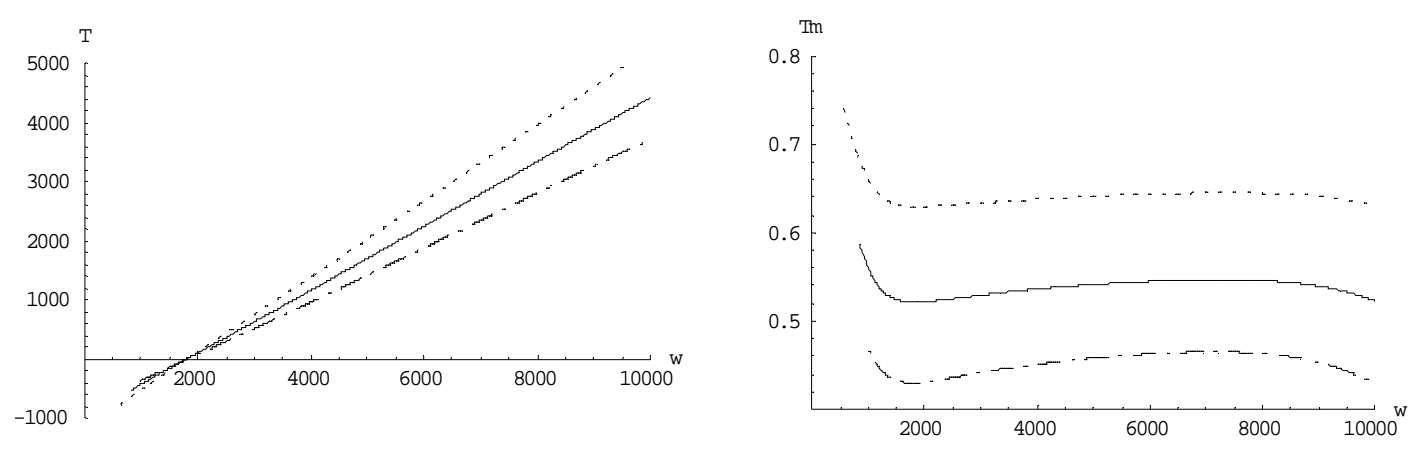

Figure 7: Dotted, solid and dashed lines respectively for $d$ equal to 300, 500 and 700 Euros. 


\section{III.3.3 The labor demand elasticity and the bargaining power}

Since we assume the Hosios condition to be satisfied, any change in the elasticity of the matching function $\gamma$ implies an equivalent change in the workers' bargaining power. The higher the level of $\gamma$, the higher is the matching effectiveness of searching workers. If $\gamma \rightarrow 1$, frictions on the labor market disappear. Hence, as $\gamma$ increases, labor demand becomes less elastic to the firm's expected surplus (see Equation (6)). Thus, taxation becomes less distortive. Consequently, marginal tax rates shift upwards (see Figure 8). Furthermore, a rise in $\gamma$ increases levels of efficient net output ${ }^{12}$. This efficiency gain increases the expected surplus of all participating types. Hence, participation increases. This improvement in efficiency is shared with the non-participating types through an increase in the assistance benefit $b$ (see Table 2).
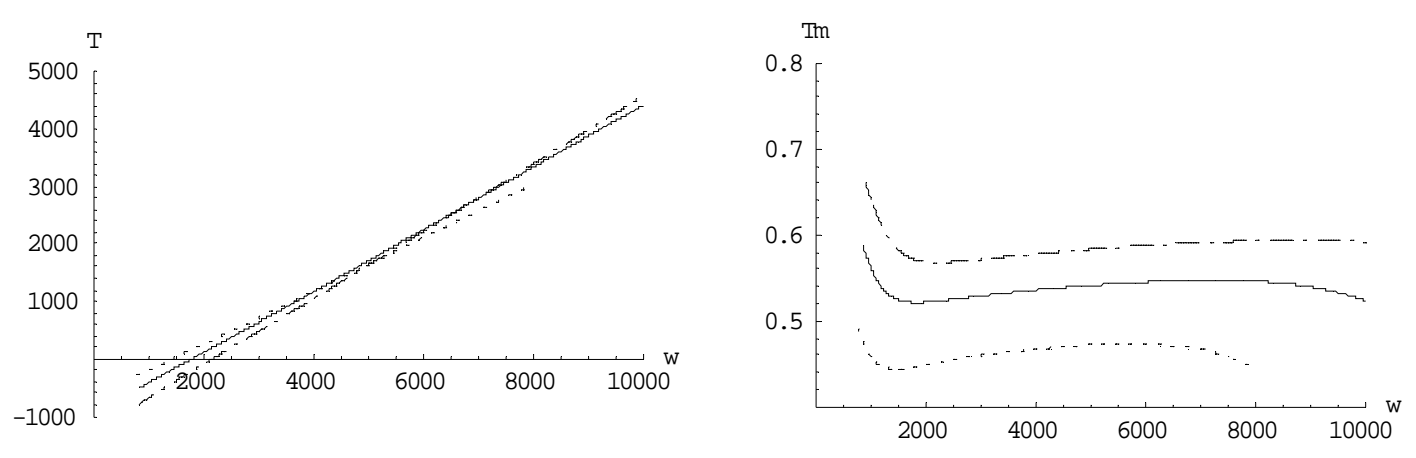

Figure 8: Dotted, solid and dashed lines respectively for $\gamma$ equal to $0.4,0.5$ and 0.6.

\section{III.3.4 The form of the distribution}

In Figure 9 and Table 2, we report the effects of a decrease in $\mu$ (dashed lines) and of a rise in $\xi$ (dotted lines).

A decrease in $\mu$ shifts the productivity distribution to the left (see Figure 4). The effects of a decline in $\mu$ and of a rise in $d$ are therefore very similar. The impact on participation is negative. To restore a balanced budget, assistance benefits $b$ decrease and the decline in participation is attenuated. For the latter purpose, expected utility levels are increased. Therefore, wages are less distorted and marginal tax rates shift downwards in Figure 9.

A rise in $\xi$ implies a higher dispersion of productivities (see Figure 4). Therefore, there are more low productivity workers whose expected utility levels are highly valued by the government. There are also more high productivity workers whose expected utility levels have a lower social value. Consequently, in the equity-efficiency trade-off, the government puts more emphasis on redistribution. Therefore, marginal tax rates and the level of assistance benefit increase, while participation decreases. These results are similar to those obtained by Kanbur and Tuomala (1994) in a Mirrlees-type model of optimal income taxation.

\footnotetext{
${ }^{12}$ The vacancy costs are recalibrated to keep the top and bottom values of the unemployment rate in the economy without taxes unchanged. Then, total efficient net output $Y^{*}$ increases from 1430 to 1794 and to 2155 as $\gamma$ increases from 0.4 to 0.5 and 0.6 .
} 

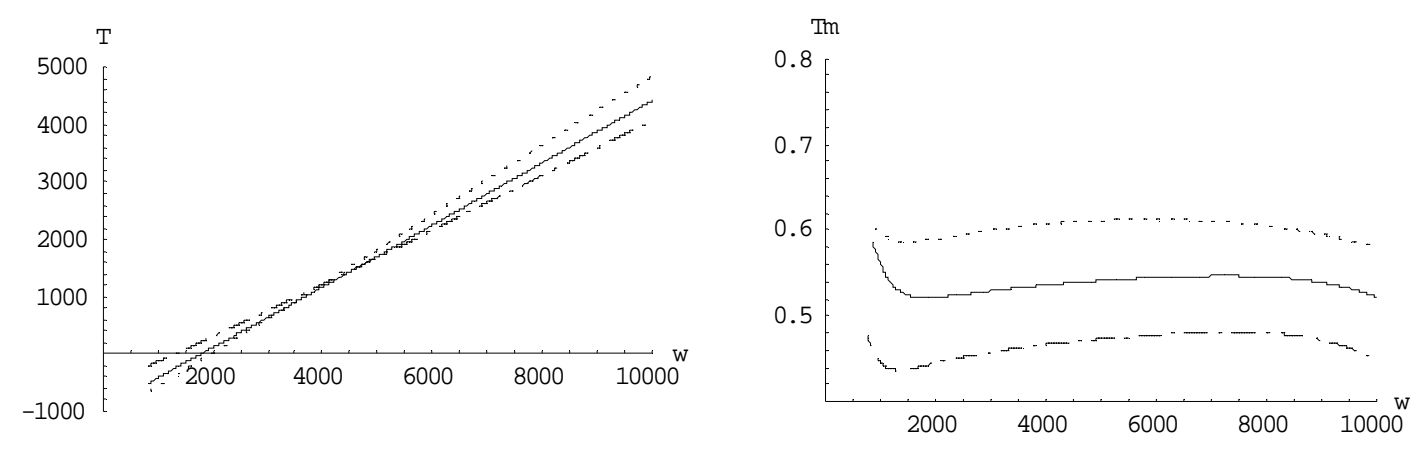

Figure 9: Dotted, solid and dashed lines respectively for $(\mu ; \xi)=(0.2 ; 0.6),=(0.2 ; 0.4)$ and $=(0.15 ; 0.4)$.

\section{III.3.5 Public expenditure}

When public expenditure increases to 359 (which amounts to $20 \%$ of total efficient net output $Y^{*}$ ) marginal tax rates are almost unaffected. The main difference is a reduction in the assistance benefit (see Table 2) and an increase in the level of taxes by about the same amount as the rise in public expenditure. Similar conclusions hold for different values of public expenditure. According to our simulation results, the optimal way of financing public expenditure is therefore mainly through lump-sum taxes.

\section{Comparing the Mirrlees approach to ours}

Our main contribution is methodological since we construct a model where the efficiency distortions induced by income taxation are due to matching frictions and wage bargaining instead of the standard consumption-leisure trade-off. Economists do observe the distribution of wages and the elasticity of gross earnings with respect to the marginal tax rate. Both the labor supply-Mirrlees approach and the bargaining-matching model are consitent with this observed elasticity. To what extent the optimal tax schedule is sensitive to the micro-foundation of this elasticity is the question we now address.

To compare our model to a framework that only incorporates the labor supply choice of the individuals, we build a model à la Mirrlees (1971) that generates the same distribution of wages and the same elasticity of gross earnings with respect to the marginal tax rate at the equilibrium without taxes. As e.g. Diamond (1998), we consider utility functions that are quasi-linear in consumption. The worker's surplus is now $x_{a} \equiv w_{a}-T\left(w_{a}\right)-v\left(h_{a}\right)-b$ with $v\left(h_{a}\right)$, the disutility of work, $v\left(h_{a}\right)^{\prime}>0$ and $v^{\prime \prime}\left(h_{a}\right)>0$. Let $\eta$ denote the elasticity of labor supply, so $1 / \eta=h \cdot v^{\prime \prime}(h) / v^{\prime}(h)$. Employment rates are assumed equal to 1 . Net output is given by $Y_{a}=a \cdot h_{a}-v\left(h_{a}\right)$ and gross wages $w_{a}$ are equal to $a \cdot h_{a}$. Labor supply $h_{a}$ solves:

$$
v^{\prime}\left(h_{a}\right)=a \cdot\left(1-T^{\prime}\left(a \cdot h_{a}\right)\right)
$$

$\Sigma_{a}$ now corresponds to the workers' surplus for an optimal labor supply:

$$
\Sigma_{a}=x_{a}=a \cdot h_{a}-v\left(h_{a}\right)-T\left(a \cdot h_{a}\right)-b
$$



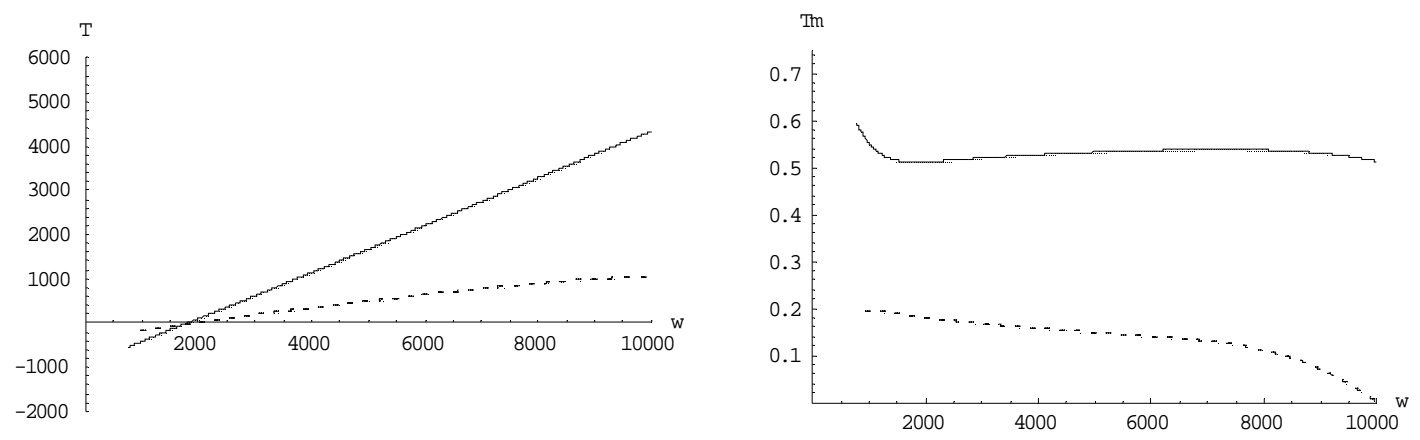

Figure 10: Benchmark comparison of the two models. Dotted lines for the Mirrlees model.

and evolves according to:

$$
\dot{\Sigma}_{a}=h_{a}\left(1-T^{\prime}\left(w_{a}\right)\right)=h_{a} \frac{v^{\prime}\left(h_{a}\right)}{a}
$$

In this setting à la Mirrlees, the optimal income taxation solves:

$$
\begin{aligned}
& \max _{a_{d}, h_{a}, \Sigma_{a}, b} F\left(a_{d}\right) \Phi(b+d)+\int_{a_{d}}^{a_{1}} \Phi\left(\Sigma_{a}+b\right) f(a) d a \\
& \text { s.t. : } \int_{a_{d}}^{a_{1}}\left\{a \cdot h_{a}-v\left(h_{a}\right)-\Sigma_{a}\right\} \cdot f(a) d a=b+E \\
& \dot{\Sigma}_{a}=h_{a} \frac{v^{\prime}\left(h_{a}\right)}{a} \quad\left\{\begin{array}{lll}
\Sigma_{a_{d}}=d \\
\Sigma_{a_{d}} \geq d
\end{array} \text { if } \begin{array}{l}
a_{d}>a_{0} \\
a_{d}=a_{0}
\end{array}\right.
\end{aligned}
$$

Optimal taxation verifies the following condition:

$$
\frac{T^{\prime}\left(w_{a}\right)}{1-T^{\prime}\left(w_{a}\right)}=\frac{\int_{a}^{a_{1}}\left(1-\frac{\Phi_{t}^{\prime}}{\lambda}\right) f(t) d t}{a \cdot f(a)}\left(1+\frac{1}{\eta}\right)
$$

which coincides with the classic formula provided by the standard optimal income taxation literature when utility is quasi-linear in consumption (see e.g. Diamond (1998)).

To compare it with the benchmark model of Sections II and III, we calibrate the Mirrlees model in such a way that in the economy without taxes, both models have the same distributions of wages ${ }^{13}$ and the same elasticity of gross earnings with respect to one minus the marginal tax rate. This elasticity equals $1-\gamma$ in our model ${ }^{14}$, whereas it equals $\eta$ in the Mirrlees model. Hence, we take $\eta=0.5$.

As Figure 10 and Table 3 show, the differences between the Mirrlees setting and ours are quantitatively very important. The optimum is much more redistributive when wages are bargained over and the intensive margin of the labor supply is neglected. Marginal tax rates are more than twice as high. Assistance benefits are almost three times greater. Compared to the economy without taxes, the gain in welfare $\Delta \Phi^{-1}(\Omega)$ is considerably higher and the loss in net output $\Delta Y$ is much lower. Furthermore, the profile of marginal tax rates is substantially different.

\footnotetext{
${ }^{13}$ This implies that the distribution of abilities in the "Mirrlees setting" has been appropriately reparametrized.

${ }^{14}$ From Equation (12), we evaluate $\frac{\partial w_{a}}{\partial\left(1-T_{a}^{\prime}\right)} \frac{1-T_{a}^{\prime}}{w_{a}}$ at $T_{a}^{\prime}=T_{a}=b=0$.
} 


\begin{tabular}{|c|c|rcc|rrr|r|c|}
\hline Model & Distribution & \multicolumn{3}{|c|}{ Net output $Y$} & \multicolumn{3}{|c|}{ Welfare $\Phi^{-1}(\Omega)$} & $b$ & Participation \\
& & WT & SB & $\Delta$ & WT & SB & \multicolumn{1}{c|}{$\Delta$} & & SB \\
\hline Our & Benchmark & 1794 & 1747 & $-2.7 \%$ & 1627 & 1738 & $6.8 \%$ & 809 & $94.0 \%$ \\
\hline Mirrlees & Benchmark & 2162 & 1957 & $-9.5 \%$ & 1335 & 1365 & $2.3 \%$ & 262 & $98.8 \%$ \\
\hline Our & With Pareto & 2378 & 2305 & $-3.1 \%$ & 1905 & 2258 & $18.5 \%$ & 1254 & $93.7 \%$ \\
\hline Mirrlees & With Pareto & 2748 & 2340 & $-14.7 \%$ & 1538 & 1652 & $7.5 \%$ & 422 & $99.0 \%$ \\
\hline
\end{tabular}

Table 3: Numerical results WT for the economy without taxes and SB for second best. $Y$ denotes aggregate net output, i.e. $Y=\int_{a_{d}}^{a_{1}} Y_{a} f(a) d a$.

We explain in two stages why our marginal tax rates are above those found in the Mirrlees approach. We first explain why this property would hold even if efficiency was reached in the two settings. Next, we argue that this property is reinforced when tax rates deviate from their efficient values because they are optimally chosen for redistributive purposes.

In the Mirrlees model, efficient marginal tax rates are necessarily equal to zero since any positive marginal tax rate would distort labor supply. In our model, since Hosios (1990), we know that efficiency can be reached in an economy without taxes and benefits. In an economy with redistributive taxation, efficiency can, however, also be achieved under the Hosios condition if marginal tax rates are efficient i.e. if they verify (14) (see Boone and Bovenberg 2002). From this expression, efficient marginal tax rates are positive if $T_{a}+b$ is positive. This condition sounds plausible if redistribution matters. It is actually verified by the second-best optimum (according to Propositions 4 and 5). To sum up, if the solutions to the problem addressed respectively by Mirrlees and by us were both compatible with efficiency, the marginal tax rates would be higher in a frictional economy than in a competitive frictionless labor market.

Second, in both models, marginal tax rates are above their efficient values, except at the top of the distribution. As we move to the left of the distribution, the fraction of workers potentially involved in mimicking others increases. This generates a greater and greater upward pressure on marginal tax rates. In our model, the incentive compatibility constraint is expressed in terms of growth rates of workers' expected surplus (see Equation 16). In the Mirrlees version, the incentive constraint is formulated in terms of absolute changes (see Equation 21). Hence, in our model the upward pressure on marginal tax rates is stronger at the low end of the distribution.

Figure 10 assumes a log-normal distribution. However, within the Mirrlees approach, the tax schedule is highly sensitive to the skill distribution chosen. In particular, several authors (Diamond (1998) and Saez (2001)) have recently moved away from the log-normal assumption. They argue that the upper part of the productivity distribution is better approximated by an unbounded Pareto function. Under this assumption, they show that optimal marginal tax rates are much higher at the top of the distribution. Therefore, we conduct a sensitivity analysis. We take the same log-normal distribution as before for the lower part of the distribution but we assume a Pareto distribution with density $f_{\text {par }}(a)=K_{p} / a^{1+\pi}$ for the upper part. Following Saez (2001), we take $\pi=2$. The boundary between the two densities and $K_{p}$ are chosen in such a way that the entire distribution is continuously differentiable. This leads to a boundary productivity level of $a_{\lim }=5510$. For this distribution, Figure 11 and the two bottom lines of Table 3 compare 

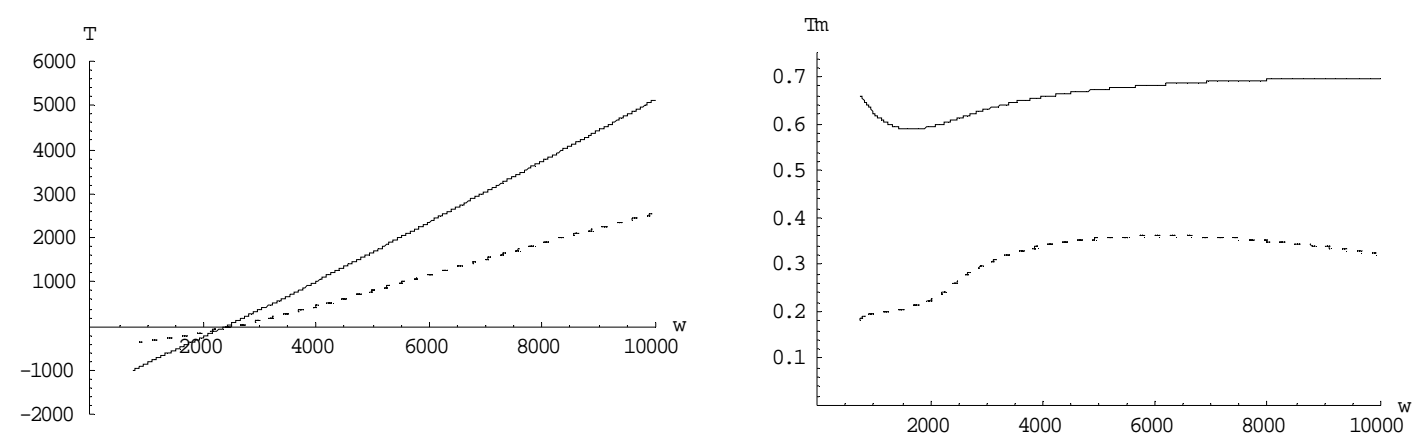

Figure 11: Comparison of the two models with a Pareto function at the top of the distribution. Dotted lines for the Mirrlees model.

the properties of our optimum to the Mirrlees ones ${ }^{15}$. As expected, compared to the log-normal distribution, marginal tax rates are much higher in the upper part of the wage distribution when hours are endogenous and the labor market is purely competitive. Our optimal marginal tax rates increase also, but to a lesser extent. More importantly, our marginal tax rates remain higher than those computed in the Mirrlees approach. So, this property appears to be robust to the choice of the distribution of productivity levels.

\section{Conclusion}

The optimal income taxation literature has essentially focused on distortions created through the consumption-leisure trade-off. This trade-off is, however, not the unique way of explaining that earnings are affected by the profile of taxes. We have adopted an alternative setting where frictions on the labor market generate involuntary unemployment and rents to be shared by employers and employees. In this framework with exogenous working hours, the optimal income taxation has properties that strongly differ from those found in the Mirrlees competitive setting. Unemployment is lower than at the equilibrium without taxes, average tax rates are increasing in wages and marginal tax rates are strictly positive including those at the top of the wage distribution. Compared to the prescriptions of a comparable Mirrlees setting, our numerical simulations show that both marginal tax rates and assistance benefits are always at least twice as high.

In sum, estimating the elasticity of gross earnings with respect to taxes is not sufficient to derive clear policy recommendations about the optimal tax schedule. The elasticity of gross earnings with respect to the marginal tax rate is estimated around 0.5 (see e.g. Gruber and Saez (2002)). The empirical support that this elasticity can be explained by the labor supply mechanism is however rather low: The elasticity of hours worked with respect to the marginal tax rate is often found to be close to 0 for men, though estimates are more dispersed and generally higher for women (see the survey of Blundell and MaCurdy (1999)). The empirical literature on the wage-bargaining effect has in most cases found a significant positive elasticity (see Røed and Strøm (2002) and Sørensen (1997) for overviews on the literature). However, results are quite dispersed and the estimates are often based on time series of average wages rather than on individual panel

\footnotetext{
${ }^{15}$ To approximate an unbounded distribution, we now truncate the Pareto distribution at $a_{1}=40000$, but we report results for $a \in\left[a_{0}, 20000\right]$.
} 
data. Hence, further research is needed to clarify which theoretical setting is empirically the most relevant.

This paper also points to many interesting theoretical extensions. First, the assumption that employment is efficient in the no tax equilibrium could be relaxed (see Hungerbühler (2004)). Second, the modeling of the extensive margin could be enriched. Finally, our contribution has been essentially methodological. Numerical simulations have therefore not tried to exploit rich datasets. All these extensions have also been left for further research.

\section{Appendix}

\section{A The first-best optimum}

The first-order conditions of problem (8) are for each $a$ :

$$
\begin{aligned}
& 0=\left\{\Phi^{\prime}\left(\Sigma_{a}+b\right)-\lambda\right\} p_{a} \cdot f(a) \\
& 0=\int_{a_{0}}^{a_{1}}\left\{p_{a} \cdot \Phi^{\prime}\left(\Sigma_{a}+b\right)+\left(1-p_{a}\right) \Phi^{\prime}(b+d)\right\} f(a) d a-\lambda \\
& 0=\lambda \cdot \frac{\partial Y_{a}}{\partial w_{a}} \cdot p_{a} \cdot f(a) \\
& p_{a}=\left\{\begin{array}{lll}
1 & \text { if } \quad 0 & \leq \\
0 & &
\end{array} \quad\left\{\left(\Sigma_{a}+b\right)-\Phi(b+d)+\lambda\left[Y_{a}\left(w_{a}\right)-\Sigma_{a}\right]\right\} f(a) \quad\left(p_{a}\right)\right.
\end{aligned}
$$

where $\lambda$ is the Lagrange Multiplier of the budget constraint.

Hence, at the first-best optimum, every participating type receives the same expected surplus $\Sigma_{a}^{*}$ whose value is defined by $\Phi^{\prime}\left(b+\Sigma_{a}^{*}\right)=\lambda$. Taking the condition on $b$ into account, one further gets $\lambda=\Phi^{\prime}\left(\Sigma_{a}^{*}+b\right)=\Phi^{\prime}(b+d)$ so $\Sigma_{a}^{*}=d$. The condition on $w_{a}$ means that the wage level is fixed at its efficient value, $w_{a}^{*}$. From Equation (7), we then have:

$$
\frac{\partial Y_{a}}{\partial w_{a}}=\frac{\gamma \cdot a-w_{a}}{\gamma}\left(a-w_{a}\right)^{\frac{1}{\gamma}-2} \cdot \kappa_{a}^{\frac{\gamma-1}{\gamma}}
$$

Therefore, the efficient wage $w_{a}^{*}$ equals $\gamma \cdot a$.

Finally, the condition on participation can be simplified as:

$$
p_{a}= \begin{cases}1 & \text { if } \quad d \leq Y_{a}\left(w_{a}^{*}\right) \\ 0 & \end{cases}
$$

Hence, every type above (below) $a_{d}^{*}$ should participate (be inactive) at the first best, where $a_{d}^{*}$ is the unique solution in $a$ to:

$$
Y_{a}\left(w_{a}^{*}\right)=d
$$

\section{B The second-best optimum}

\section{B.1 The incentive compatibility constraints}

This section follows Salanié (1997) very closely. Let $\mathcal{N}(a, t)$ be the logarithm of the Nash product for a type- $a$ job when the negotiated wage is the one designed for type $t$-jobs. So

$$
\mathcal{N}(a, t) \equiv \log N\left(a, w_{t}, x_{t}\right)=\frac{1-\gamma}{\gamma} \log \left(\frac{a-w_{t}}{\kappa_{a}}\right)+\log \left(w_{t}-T\left(w_{t}\right)-b\right)+\frac{1}{\gamma} \log A
$$


and ${ }^{16}$ :

$$
\frac{\partial \mathcal{N}}{\partial a}(a, t)=\frac{1-\gamma}{\gamma}\left(\frac{1}{a-w_{t}}-\frac{\dot{\kappa}_{a}}{\kappa_{a}}\right) \quad \frac{\partial^{2} \mathcal{N}}{\partial a \partial t}(a, t)=\frac{1-\gamma}{\gamma} \frac{\dot{w}_{t}}{\left(a-w_{t}\right)^{2}}
$$

Equation (17) means that the function $t \longmapsto \mathcal{N}(a, t)$ reaches a maximum for $t=a$. So, $\log \Sigma_{a}=\mathcal{N}(a, a)$. The first-order condition can be written as $\frac{\partial \mathcal{N}}{\partial t}(a, a)=0$. So, for any $a$

$$
\frac{\dot{\Sigma}_{a}}{\Sigma_{a}}=\frac{\partial \mathcal{N}}{\partial a}(a, a)+\frac{\partial \mathcal{N}}{\partial t}(a, a)=\frac{\partial \mathcal{N}}{\partial a}(a, a)
$$

which, combined with (23) leads to (16). Furthermore, since $\frac{\partial \mathcal{N}}{\partial t}(a, a)=0$ for all $a$, one has $\frac{\partial^{2} \mathcal{N}}{\partial t \partial a}(a, a)+\frac{\partial^{2} \mathcal{N}}{\partial t \partial t}(a, a)=0$. So, the second-order condition $\frac{\partial^{2} \mathcal{N}}{\partial t \partial t}(a, a)<0$ is equivalent to $0<\frac{\partial^{2} \mathcal{N}}{\partial t \partial a}(a, a)$ for all $a$. From $(23)$ the second-order condition requires that for all $a$ :

$$
\dot{w}_{a}>0
$$

Finally, one has to verify that these local conditions are sufficient for (17). For any $a$ and any $t \neq a$ there exists $\theta \in(0,1)$ such that for $\hat{t}=\theta a+(1-\theta) t$

$$
\mathcal{N}(a, a)-\mathcal{N}(a, t)=\frac{\partial \mathcal{N}}{\partial t}(a, \hat{t}) \cdot(a-t)
$$

Provided that for all $t, \dot{w}_{t}>0$, one has $\frac{\partial^{2} \mathcal{N}}{\partial a \partial t}(a, t)>0$ and therefore $\frac{\partial \mathcal{N}}{\partial t}(a, t)$ is increasing in $a$. Since $\frac{\partial \mathcal{N}}{\partial t}(\hat{t}, \hat{t})=0$, this implies that $\frac{\partial \mathcal{N}}{\partial t}(a, \hat{t}) \gtrless 0$ if $a \gtrless \hat{t}$, that is if $a \gtrless t$. Hence $\frac{\partial \mathcal{N}}{\partial t}(a, \hat{t}) \cdot(a-t)>0$ and $t=a$ is a global maximum for $t \longmapsto \mathcal{N}(a, t)$.

\section{B.2 The first-order conditions of the optimization problem}

We solve problem (18) in two steps. First, we solve for given values of $b$ and $a_{d}$. Second, we characterize the optimal values of $b$ and $a_{d}$. Given $b$ and $a_{d}$, we define the Hamiltonian for $a \in\left[a_{d}, a_{1}\right]$ as:

$$
\mathbb{H}_{a}=\left\{\Phi\left(\Sigma_{a}+b\right)+\lambda \cdot Y_{a}\left(w_{a}\right)-\lambda \cdot \Sigma_{a}\right\} f(a)+q_{a} \cdot \frac{1-\gamma}{\gamma}\left(\frac{1}{a-w_{a}}-\frac{\dot{\kappa}_{a}}{\kappa_{a}}\right) \Sigma_{a}
$$

where $\lambda$ is the Lagrange multiplier associated with the budget constraint and $q$ is the co-state variable. The necessary conditions are:

$$
\begin{aligned}
0 & =\lambda \cdot \frac{\partial Y_{a}}{\partial w_{a}} \cdot f(a)+q_{a} \cdot \Sigma_{a} \cdot \frac{1-\gamma}{\gamma\left(a-w_{a}\right)^{2}} \\
-\dot{q}_{a} & =\left\{\Phi_{a}^{\prime}-\lambda\right\} f(a)+q_{a} \frac{\dot{\Sigma}_{a}}{\Sigma_{a}}
\end{aligned}
$$

and the transversality conditions are:

$$
q_{a_{d}} \cdot\left[\Sigma_{a_{d}}-d\right]=0 \quad q_{a_{1}}=0
$$

As usual, $q_{a}$ is the shadow cost of a marginal increase in $\Sigma_{a}$. Define $Z_{a}=q_{a} \cdot \Sigma_{a}$. The condition for $\Sigma_{a}$ implies:

$$
-\dot{Z}_{a}=\left\{\Phi_{a}^{\prime}-\lambda\right\} \Sigma_{a} f(a)
$$

\footnotetext{
${ }^{16}$ It is here assumed that the mechanism $a \rightarrow(w(a), x(a))$ is differentiable so $\dot{w}_{a}$ exists.
} 
So, together with the transversality condition, one gets:

$$
Z_{a}=\int_{a}^{a_{1}}\left\{\Phi_{t}^{\prime}-\lambda\right\} \Sigma_{t} \cdot f(t) \cdot d t
$$

$Z_{a}$ corresponds to the opposite of the integral on the right hand side of Equation (19). Since $Z_{a} \cdot \frac{d \Sigma_{a}}{\Sigma_{a}}=q_{a} \cdot d \Sigma_{a}, Z_{a}$ stands for the shadow cost of a relative marginal increase in $\Sigma_{a}$.

The first order condition w.r.t. $w_{a}$ can be written as

$$
\lambda \cdot \frac{\partial Y_{a}}{\partial w_{a}} \cdot f(a)=-Z_{a} \frac{1-\gamma}{\gamma\left(a-w_{a}\right)^{2}}
$$

which, together with the expression (26) for $Z_{a}$ gives (19). The conditions with respect to $b$ and $a_{d}$ are (see Leonard and Van Long (1992)):

$$
\begin{aligned}
& \int_{a_{0}}^{a_{1}}\left(\Phi_{a}^{\prime}-\lambda\right) f(a) d a=0 \\
& \Phi(b+d) f\left(a_{d}\right)-\mathbb{H}_{a_{d}} \leq 0 \quad \text { with }=\text { if } a_{d}>a_{0}
\end{aligned}
$$

\section{B.2.1 Proof of Propositions 1 and 2}

For $a=a_{1}$, the transversality condition $q_{a_{1}}=0$ implies that the integral on the right hand side of Equation (19) is nil for $a=a_{1}$, so $w_{a_{1}}=w_{a_{1}}^{*}$ and $L_{a_{1}}=L_{a_{1}}^{*}$.

For $a \in\left[a_{d}, a_{1}\right)$ : Since $\Sigma_{a}$ is increasing in $a$ by Equations (1) and (16), $\Phi_{a}^{\prime}$ is decreasing in $a$. Equation (28) implies that there exists a unique $\hat{a}$ such that $\Phi_{\hat{a}}^{\prime}=\lambda$. For $t<\hat{a}$, we get $\Phi_{t}^{\prime}-\lambda>0$ and $\Sigma_{t}<\Sigma_{\hat{a}}$ and for $t>\hat{a}$, we get $\Phi_{t}^{\prime}-\lambda<0$ and $\Sigma_{t}>\Sigma_{\hat{a}}$. Therefore, for any $t \neq \hat{a}$, we have $\left(\Phi_{t}^{\prime}-\lambda\right) \Sigma_{t}<\left(\Phi_{t}^{\prime}-\lambda\right) \Sigma_{\hat{a}}$. Using this inequality and Equations (26) and (28), we obtain:

$$
\begin{aligned}
Z_{a} & =\int_{a}^{a_{1}}\left(\Phi_{t}^{\prime}-\lambda\right) \Sigma_{t} \cdot f(t) \cdot d t<\int_{a}^{a_{1}}\left(\Phi_{t}^{\prime}-\lambda\right) \Sigma_{\hat{a}} \cdot f(t) \cdot d t \\
& <\Sigma_{\hat{a}}\left[\int_{a}^{a_{1}} \Phi_{t}^{\prime} \cdot f(t) \cdot d t-\lambda(1-F(a))\right]=\Sigma_{\hat{a}} \cdot(1-F(a)) \cdot\left\{\mathbb{E}_{f}\left[\Phi_{t}^{\prime} \mid t \geq a\right]-\lambda\right\}
\end{aligned}
$$

where:

$$
\mathbb{E}_{f}\left[\Phi_{t}^{\prime} \mid t \geq a\right]=\frac{\int_{a}^{a_{1}} \Phi_{t}^{\prime} \cdot f(t) d t}{1-F(a)}
$$

Hence:

$$
\left.Z_{a}<\Sigma_{\hat{a}} \cdot(1-F(a)) \cdot\left\{\mathbb{E}_{f}\left[\Phi_{t}^{\prime} \mid t \geq a\right]-\mathbb{E}_{f}\left[\Phi_{t}^{\prime} \mid t \geq a_{0}\right]\right]\right\}
$$

by Equation (28). Therefore, $Z_{a}$ is negative for all $a<a_{1}$ because $\Phi_{t}^{\prime}$ is decreasing with respect to the productivity $t$. From (27), we obtain $\partial Y_{a} / \partial w_{a}>0$, so from (22), we have $w_{a}<w_{a}^{*}$ and over-employment for all types $a \in\left[a_{d}, a_{1}\right)$.

\section{B.2.2 Proof of Propositions 3 and 4}

We will prove that $a_{d} \geq a_{d}^{*}$. From the first-order condition on $a_{d}$, we have:

$0 \geq f\left(a_{d}\right) \Phi(b+d)-\left\{\Phi\left(\Sigma_{a_{d}}+b\right)+\lambda \cdot\left(Y_{a_{d}}-\Sigma_{a_{d}}\right)\right\} f\left(a_{d}\right)-Z_{a_{d}} \frac{1-\gamma}{\gamma}\left[\frac{1}{a_{d}-w_{a_{d}}}-\frac{\dot{\kappa}_{a_{d}}}{\kappa_{a_{d}}}\right]$ 
Since $Z_{a}$ is always negative for $a<a_{1}$, the transversality condition on $a_{d}$ implies that $\Sigma_{a_{d}}=d$. Rearranging the terms, we get:

$$
Y_{a_{d}}-\Sigma_{a_{d}} \geq-\frac{Z_{a_{d}}}{\lambda \cdot f\left(a_{d}\right)} \cdot \frac{1-\gamma}{\gamma}\left[\frac{1}{a_{d}-w_{a_{d}}}-\frac{\dot{\kappa}_{a_{d}}}{\kappa_{a_{d}}}\right]>0
$$

So, $d=\Sigma_{a_{d}}<Y_{a_{d}}$. Furthermore, we get $Y_{a_{d}}<Y_{a_{d}}^{*}$ since $Y_{a_{d}}^{*}$ corresponds to the efficient value at $a_{d}$. Hence, we get

$$
Y_{a_{d}}^{*}>d
$$

So, given Equation (10) we have two possible cases. First, $a_{d}=a_{0}=a_{d}^{*}$. Second, $a_{d}>a_{0}$ with $Y_{a_{d}}^{*}>Y_{a_{d}^{*}}^{*}=d$, which implies that $a_{d}>a_{d}^{*}$.

$Y_{a_{d}}>\Sigma_{a_{d}}$ implies $w_{a_{d}}>x_{a_{d}}$ so $T_{a_{d}}+b>0$ and $b>-T_{a_{d}}$.

\section{B.2.3 Proof of Proposition 5}

From Equations (9) and (13) the gross wage is below its efficient level if and only if

$$
T_{a}^{\prime}>\frac{T_{a}+b}{w_{a}}
$$

Since

$$
\frac{\partial\left(\frac{T\left(w_{a}\right)}{w_{a}}\right)}{\partial w_{a}}=\frac{T_{a}^{\prime}-\frac{T\left(w_{a}\right)}{w_{a}}}{w_{a}}
$$

Proposition 2 implies that the average tax rate is increasing in the wage. Finally, according to Proposition 4, one has $T^{\prime}\left(w_{a}\right)>\left(T\left(w_{a}\right)+b\right) / w_{a} \geq\left(T\left(w_{a_{d}}\right)+b\right) / w_{a_{d}}>0$.

\section{References}

[1] Blanchard, O. J. and Diamond, P., 1989, "The Beveridge Curve", Brookings Papers on Economic Activity, 1, 1-76.

[2] Blundell, R. and MaCurdy, T. ,1999, "Labor Supply: A Review of alternative approaches", in O. Ashelfelter and D. Card (eds), Handbook of Labor Economics, NorthHolland.

[3] Boadway, R., Cuff, K. and Marchand, M. , 2000, "Optimal Income Taxation with Quasi-Linear Preferences Revisited", Journal of Public Economic Theory, 2, 435-60.

[4] Boone, J. and Bovenberg, L., 2002, "Optimal Labor Taxation and Search", Journal of Public Economics, 85, 53-97.

[5] Boone, J. and Bovenberg, L., 2004, "The optimal taxation of unskilled labor with job search and social assistance", Journal of Public Economics, 88(11), 2227-2258.

[6] Boone, J. and Bovenberg L., 2005, "Optimal welfare and in-work benefits with search unemployment and observable abilities", Journal of Economic Theory, Forthcoming.

[7] Cremer, J. and McLean, R., 1988, "Full Extraction of the Surplus in Bayesian and Dominant Strategy Auctions", Econometrica, 56(6), 1247-1258. 
[8] Diamond, P. 1998, "Optimal Income Taxation: An Example with a U-Shaped Pattern of Optimal Marginal Tax Rates", American Economic Review, 88, 83-95.

[9] Engström, P., 2002, "Optimal Non-Linear Taxation in Search Equilibrium", Working Paper 2002:18, Uppsala University.

[10] Feldstein, M., 1995, "The Effect of Marginal Tax Rates on Taxable Income: A Panel Study on the 1986 Tax Reform Act", Journal of Political Economy, 103 (3), 551-572.

[11] Guesnerie, R., 1995, "A contribution to the pure theory of taxation", Cambridge University Press.

[12] Gruber, J. and Saez, E., 2002, "The elasticity of taxable income: evidence and implications", Journal of Public Economics, 84(1), 1-32.

[13] Hammond, P, 1979, Straightforward Individual Incentive Compatibility in Large Economies, Review of Economic Studies, 46(2), 263-282.

[14] Holmlund, B and Kolm, A. S 1995, "Progressive Taxation, Wage setting, and Unemployment : Theory and Swedish evidence", Swedish Economic Policy Review 2, 423-460.

[15] Hosios, A.,1990, "On the Efficiency of Matching and Related Models of Search and Unemployment", Review of Economic Studies, 57, 279-298.

[16] Hungerbühler, M., 2004, "The Impact of Union Power on the Optimal Income Tax Schedule", IRES Discussion Paper n 2004 - 34, Université Catholique de Louvain, Louvain La Neuve, Belgium.

[17] Hungerbühler, M., Lehmann, E., Parmentier, A. and Van der Linden, B., 2005, "Optimal Redistributive Taxation in a Search Equilibrium Model", IZA Discussion Paper $\mathrm{n}^{\circ} 1470$.

[18] Kanbur, R. and Tuomala, R., 1994, "Inherent Inequality and the Optimal Graduation of Marginal Tax Rates", Scandinavian Journal of Economics, 96(2), 275-282.

[19] Laffont, J. J and Martimort, D., 2002, The theory of incentives: the principal agent model, Princeton University Press.

[20] Leonard, D. and Van Long N., 1992, Optimal control theory and static optimization in economics, Cambridge University Press.

[21] Lockwood B. and Manning A., 1993, "Wage Setting and the Tax System: Theory and evidences for the United Kingdom", Journal of Public Economics, 52, 1-29.

[22] Malcomson, J. M. and Sartor, N., 1987, "Tax Push Inflation in a Unionized Labour Market", European Economic Review, 31, 1581-1596.

[23] Mirrlees, J., 1971, "An Exploration in the Theory of Optimum Income Taxation", Review of Economic Studies, 38, 175-208.

[24] Moen, E., 1997, "Competitive Search Equilibrium", Journal of Political Economy, $105(2), 385-411$. 
[25] Mortensen, D. and Pissarides, C., 1999, "New developments in models of search in the Labor Market", in O. Ashenfelter and D. Card (eds.), Handbook of Labor Economics, vol 3 (North-Holland, Amsterdam).

[26] Petrongolo, B. and Pissarides, C. A. , 2001, "Looking into the Black Box: A Survey of the Matching Function", Journal of Economic Literature, 38, 390-431.

[27] Pissarides, C. A., 1998, "The impact of employment tax cuts on unemployment and wages: the role of unemployment benefits and tax structure", European Economic Review, 42, 155-183.

[28] Pissarides, C. A., 2000, Equilibrium Unemployment Theory, Second Edition,MIT Press, Cambridge, US (First edition published in 1990 by Basil Blackwell).

[29] Røed, K. and Strøm, S., 2002, Progressive Taxes and the Labour Market: Is the Tradeoff Between Equality and Efficiency Inevitable?, Journal of Economic Surveys, 16(1), 77-110.

[30] Salanié, B., 1997, The Economics of Contracts: a Primer, MIT Press.

[31] Saez, E., 2001, "Using Elasticities to Derive Optimal Income Tax Rates", Review of Economic Studies, 68, 205-229.

[32] Saez, E., 2002, "Optimal Income Transfers Programs: Intensive versus Extensive Margin Labor Supply", Quarterly Journal of Economics, 117, 1039-1073.

[33] Sørensen, P. B., 1997, Public finance solutions to the European unemployment problem?", Economic Policy, 25, 223-264

[34] Sørensen, P. B., 1999 , "Optimal Tax Progressivity in imperfect Labour markets", Labour Economics, 6, 435-452.

[35] Stiglitz, J. E., 1982, "Self-Selection and Pareto Efficient Taxation", Journal of Public Economics, 17,213-240.

[36] Tuomala, M., 1990, Optimal Income Tax and Redistribution, Oxford: Clarendon Press. 